\title{
Prolactin modulates TNBC aggressive phenotype limiting tumorigenesis
}

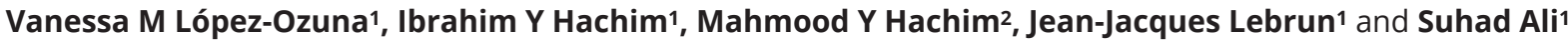 \\ 'Department of Medicine, Cancer Research Program, McGill University Health Centre, McGill University, Montreal, Québec, Canada \\ 2Sharjah Institute for Medical Research, University of Sharjah, Sharjah, United Arab Emirates
}

Correspondence should be addressed to S Ali: suhad.ali@mcgill.ca

\begin{abstract}
Triple-negative breast cancer (TNBC) accounts for $\sim 20 \%$ of all breast cancer cases. The management of TNBC represents a challenge due to its aggressive phenotype, heterogeneity and lack of targeted therapy. Loss of cell differentiation and enrichment with breast cancer stem-like cells (BCSC) are features of TNBC contributing to its aggressive nature. Here, we found that treatment of TNBC cells with PRL significantly depletes the highly tumorigenic BCSC subpopulations CD44+/CD24- and $\mathrm{ALDH}^{+}$and differentiates them to the least tumorigenic CD44-/CD24- and ALDH- phenotype with limited tumorsphere formation and self-renewal capacities. Importantly, we found PRL to induce a heterochromatin phenotype marked by histone $\mathrm{H} 3$ lysine 9 trimethylation (H3K9me3) and accompanied by ultra-structural cellular architecture associated with differentiation and senescence rendering the cells refractory to growth signals. Crucially, we found PRL to mediate these effects in vivo in a pre-clinical animal xenograft of TNBC controlling tumor growth. These results reveal that the lactogenic hormone PRL may exert its anti-tumorigenic effects on TNBC through cellular reprogramming indicative of differentiation resulting in the depletion of $\mathrm{BCSCs}$ and restricting tumorigenesis.
\end{abstract}
Key Words
- stem cell differentiation
- epigenetics regulation
- cellular plasticity
- xenografts

\section{Introduction}

Triple-negative breast cancer (TNBC) subtype accounts for about $10-20 \%$ of all breast cancer cases and is characterized by the lack of expression of estrogen receptor, progesterone receptor and human epidermal growth factor receptor 2 (HER2) (Rakha et al. 2007). TNBC represents aggressive tumors with poor prognosis and high relapse and metastatic index. It has been suggested that these aggressive features of TNBC are due to the presence of high levels of breast cancer stem-like cells (BCSCs) (Anders $\&$ Carey 2009). These BCSCs are responsible for tumor initiation, metastasis, recurrence and resistance to chemo/ radiotherapies (Kim et al. 2009). CSCs are recognized by several markers such as CD44, CD24 and the enzyme aldehyde dehydrogenase 1 (ALDH1) (Al-Hajj et al. 2003,
Ginestier et al. 2007). The adhesion molecule CD44 together with no or very low levels of CD24 identifies a highly tumorigenic stem-like cell subpopulation referred to as $\mathrm{CD} 44^{+} / \mathrm{CD} 24^{-}$. Importantly, these stem-like cells were found to be the highest population expressed in TNBC tumors and to be associated with poor prognosis (Honeth et al. 2008). ALDH1, a detoxifying enzyme involved in catalyzing the oxidation of intracellular aldehydes (Ginestier et al. 2007), was also found to label a BCSC subpopulation associated with biological aggressiveness (tumor size/stage) and poor outcomes in TNBC patients (Ma et al. 2017). Several transcription factors such as Oct4, Sox 2 and Nanog - regulators of pluripotency - are shown to significantly increase the potential of BCSCs to 
self-renew and promote metastatic invasion when they are deregulated (Rodriguez-Pinilla et al. 2007, Kim \& Nam 2011, Lu et al. 2014). Additionally, Nanog, Oct4 and Sox2 gene expression signature was found to be directly associated with high-grade TNBC basal-like subtype and with poor clinical outcome (Ben-Porath et al. 2008). Identification of factors and mechanisms contributing to the depletion and/or differentiation of TNBC BCSCs is essential to better understand TNBC biology and tumorigenesis and to help advance new treatments for this aggressive breast cancer subtype (Rangel et al. 2016).

The lactation hormone prolactin (PRL) is one of the major regulators of mammary gland development and terminal differentiation of the mammary epithelial cells allowing for successful lactation (Ormandy et al. 1997, Hennighausen \& Robinson 2005). However, its role in breast carcinogenesis is not fully elucidated. Studies have implicated PRL in promoting tumorigenesis through a PRL/PRLR autocrine loop and contributing to metastatic spread, reviewed extensively by Yonezawa et al. (2015), Sutherland et al. (2016) and Goffin (2017). Epidemiological studies suggested that the upper quartile of normal levels of circulating PRL is associated with increased risk of breast cancer development (Hankinson et al. 1999, Tworoger et al. 2013). Furthermore, studies using transgenic mice designed to overexpress PRL in mammary epithelial cells resulted in the development of mammary tumors (Wennbo et al. 1997, Rose-Hellekant et al. 2003). As well, PRL and PRLR were found to play a permissive role in oncogeneinduced mammary tumors (Vomachka et al. 2000, Oakes et al. 2007). While the above studies highlight PRL as a promoter of carcinogenesis, other studies, including ours, suggested a different role as a potential suppressor of breast tumorigenesis. We have previously shown that PRL signaling suppresses epithelial-to-mesenchymal transition and reduces the invasive properties of breast cancer cells (Nouhi et al. 2006). Moreover, expression of PRL, PRLR and the effector molecule Stat5a were found to be downregulated in breast cancer patients and breast cancer cell lines (Yamashita et al. 2006, Galsgaard et al. 2009, Nitze et al. 2013) and correlating with favorable patient outcome (Yamashita et al. 2006, Peck et al. 2012, Hachim et al. 2016a,b). Importantly, we recently demonstrated that PRL differentiation pathway is also able to identify a novel TNBC-PRLR subgroup with favorable outcome (Lopez-Ozuna et al. 2016). Moreover, an independent study of TNBC subclassification using nextgeneration sequencing showed PRL signaling pathway to be expressed in basal-like immunoactivated subtype characterized by favorable prognosis (Burstein et al. 2015).
Together, these studies emphasize that expression/ activation of PRL signaling in TNBC subtypes is indicative of favorable prognosis. Furthermore, functional studies demonstrated that activation of PRL signaling pathway suppresses the aggressive nature of TNBC cells in vitro and tumorigenesis in vivo (Lopez-Ozuna et al. 2016). Still the mechanism(s) by which PRL exerts its anti-tumorigenic effects in TNBC is yet to be characterized.

Here, we demonstrate that in TNBC cells PRL suppresses stemness while inducing features of terminal differentiation including cell cycle arrest, heterochromatin formation and resistance to growth signals. These in vitro assessments were recapitulated in vivo in a TNBC pre-clinical xenograft model resulting in suppression of tumorigenesis. Together, this study unravels new mechanisms through which PRL may induce its protective and anti-tumorigenic effects in TNBC.

\section{Materials and methods}

\section{Cell culture}

MDA-MB-453 cells (representative of the TNBC-LAR subgroup expressing PRLR) and MDA-MB-231 parental cells (representative of the TNBC-mesenchymal stem-like/ claudin-low subgroup) (Prat et al. 2010, Lehmann et al. 2011) were used to generate stable cell lines overexpressing the human long form PRLR cDNA using doxycycline (dox)-dependent lentiviral system designated as MDA-MB-231/vector and MDA-MB-231/PRLR according to manufacturer's instructions (Clontech) (Nouhi et al. 2006). All breast cancer cell lines were cultured in DMEM containing $10 \% \mathrm{FBS}$ and grown at $37^{\circ} \mathrm{C}$ in $5 \% \mathrm{CO}_{2}$.

\section{Tumor sphere formation assay}

MDA-MB-231/PRLR and MDA-MB-453 cells were treated for $72 \mathrm{~h}$ and 5 days with or without PRL, respectively. Cells were trypsinized and 1000 cells/well were plated in a 12-well low attachment plate (Corning). Cells were grown for 7 days in DMEM-free serum supplemented with B27 (Invitrogen) and hPRL (250 ng/mL).

\section{Flow cytometry analysis}

Adherent cells were dissociated into single cells by trypsin-EDTA and filtered through a $40 \mu \mathrm{m}$ nylon mesh (BD Biosciences, San Diego, CA, USA). $1 \times 10^{6}$ cells were washed with PBS containing 0.5\% FBS, incubated with anti-CD44 conjugated to APC-cy7 and anti-CD24 (c) 2019 Society for Endocrinology Published by Bioscientifica Ltd. Printed in Great Britain 
conjugated to APC (BD Biosciences). Cells were then washed with $0.5 \%$ PBS-FBS for three times. After washing, cells were analyzed with Accuri C6 flow cytometer (BD Biosciences) and Flowjo software (Tree Star Inc). The proliferation platform of this software draws gates in order to separate each generation based on unstained control. Afterwards, the different generations were analyzed with regards to geometric mean fluorescence (gMFI) of CD44. Single CD44+/CD24-, CD44+/CD24+, CD44-/CD24- and CD44-/CD24+ cell was sorted using FACSAria into either 12-well ultra-low attachment plate to perform tumor sphere analysis or to 96-well plate to perform MTT assay.

\section{ALDEFLUOR assay}

The assay was performed as per manufacturer's protocol. $1 \times 10^{6}$ MDA-MB-453 cells were centrifuged and resuspended in $1 \mathrm{~mL}$ ALDH assay buffer. Five microliters of substrate were added into the cell suspension. DEAB was used as negative control. Cells were then incubated for $40 \mathrm{~min}$ at $37^{\circ} \mathrm{C}$. Percentage of $\mathrm{ALDH}^{+}$cells were analyzed with Accuri C6 flow cytometer and Flowjo software.

\section{Cell lysis, RNA extraction and RT-qPCR}

For whole-cell lysates and western blots, cells were lysed as described previously. Total RNA from MDA-MB-231/PRLR, MDA-MB-231/vector and MDA-MB-453 cells, were isolated, reverse transcribed and used for PCR amplification as described previously (Lopez-Ozuna et al. 2016). Please see primers sequences for the various transcripts examined in extended Material and methods section.

\section{MTT assay}

MTT assays were performed as previously described (Cocolakis et al. 2001).

\section{Caspase Glo 3/7 assay}

Cells were plated in 96-well plates at 5000 cells $/ 100 \mu \mathrm{L}$ in medium supplemented with $2 \%$ FBS. Caspase $3 / 7$ activity was measured using the Caspase Glo 3/7 Assay (Promega) according to manufacturer's instructions. Cells were incubated with equal volumes of medium and Caspase Glo reagent for $30 \mathrm{~min}$ at room temperature, and luminescence was measured using the EG \& G Berthold luminometer (Bad Wildbad, Germany).

(c) 2019 Society for Endocrinology Published by Bioscientifica Ltd. Printed in Great Britain

\section{Annexin $\mathrm{V}$ apoptosis detection assay}

The assay was performed as per manufacturer's protocol. $1 \times 10^{6}$ cells were washed twice and resuspended with PBS-2\%FBS (Assay buffer). Cells were then double-stained with Annexin V conjugated to FITC and PI for $15 \mathrm{~min}$ in the dark at room temperature and then analyzed by flow cytometry.

\section{Cell cycle analysis}

Cells were harvested and washed with cold PBS, and then fixed with $70 \%$ ethanol for $30 \mathrm{~min}$ at RT. The fixed cells were washed with cold PBS twice, added $500 \mu \mathrm{L}$ DNA staining solution (including $200 \mu \mathrm{g} / \mathrm{mL}$ RNase A and $20 \mu \mathrm{g} / \mathrm{mL}$ propidium iodide staining solution) and incubated for $30 \mathrm{~min}$, and then analyzed by flow cytometry.

\section{Senescence-associated $\beta$-galactosidase assay}

SA- $\beta$-gal staining was performed using SA- $\beta$-gal staining kit (Cell signaling). MDA-MB-231/PRLR (treated and untreated with hPRL for $72 \mathrm{~h}$ ) and MDA-MB-453 (treated and untreated with hPRL for 5 days) cells were fixed by fixative solution for $15 \mathrm{~min}$, followed by $\beta$-gal solution incubation overnight at $37^{\circ} \mathrm{C}$. The staining was checked under microscope for the development of green color.

\section{Immunofluorescence microscopy}

MDA-MB-231/PRLR cells (treated and untreated with hPRL for $72 \mathrm{~h}$ ) and MDA-MB-453 cells (treated and untreated with hPRL for 5 days) were trypsinized and grown on coverslips for 1 day, next, were fixed with 3.7\% formaldehyde for $15 \mathrm{~min}$ and permeabilized in $0.1 \%$ Triton X-100 for $5 \mathrm{~min}$. Cell were then washed with PBS and blocked for $1 \mathrm{~h}$ in $2 \%$ normal donkey serum. Cells were incubated with an anti-H3K9me3 (Abcam \#176916) specific antibody for $1 \mathrm{~h}$, washed with PBS and incubated with Alexa Fluor456 goat anti-rabbit antibody and DAPI for $1 \mathrm{~h}$. Stained coverslips were mounted with SlowFade Gold antifade reagent. Confocal analysis was performed using a Zeiss LSM 510 Meta Axiovert confocal microscope using $63 \times$ objectives.

\section{Electron microscopy}

MDA-MB-453 cells were harvested and fixed at $1 \times 10^{6}$ with $2.5 \%$ glutaraldehyde for $6 \mathrm{~h}$ at $4^{\circ} \mathrm{C}$. Then, the cells were 
processed for ultra-structure analysis in the Facility for Electron Microscopy Research (FEMR), McGill University.

\section{Immunohistochemistry analysis and scoring}

Slides were incubated with a rabbit polyclonal antibody to PRLR-L (Santa Cruz \#sc-20992), Ki67 (Abcam \#16667), CD44 (Abcam \#ab51037) and H3K9me3 (Abcam \#176916). At least four different areas were randomly selected at high magnification power $(40 \times)$ for immunohistochemistry evaluation. Quantification of positive cells was done through measuring the mean of the positive cells in these different fields. For PRLR, only granular cytoplasmic staining was considered positive, and membranous staining was considered positive for CD44 staining. Nuclear stain was considered positive for both Ki-67 and H3K9me3 expressions.

\section{In silico analysis}

Prognosis gene expression analysis tool and the correlation module of Breast Cancer Gene-Expression Miner database, version 4.1 (bc-GenExMiner 4.1) were used (Jezequel et al. 2012) to examine AEFS (any event-free survival that includes 'any pejorative event: local relapse, metastatic relapse or death'). The KM plotter database was also used to examine patient outcome (RFS).

\section{Animal models}

All experimental animal work was performed in a specificpathogen-free animal facility according to the guidelines and ethical regulations of the Research Institute McGill University Health Centre-approved animal used protocol (\#2014-7492) in accordance with Canadian Council of Animal Care Guidelines. Thirty female NOD/SCID mice were purchased from Charles River Laboratories and randomly assigned into three groups according to PRL treatment: MDA-MB-231/vector, MDA-MB-231/PRLR untreated and MDA-MB-231/PRLR treated. The mice were injected in the mammary fad pat. After 8 weeks following cell implantation (reaching palpable tumors), animals were treated with doxycycline $(20 \mathrm{mg} / \mathrm{kg})$ daily. MDA-MB-231/vector and MDA-MB-231/PRLRtreated group were injected i.p. every second day with hPRL (Abcam, ab51703) $(0.1 \mu \mathrm{g} / \mathrm{g})$. Tumor growth was monitored for 3 weeks during the treatment. At the end of the experiment, mice were killed by $\mathrm{CO}_{2}$ asphyxiation and subjected to necropsy. Tumors were collected from mice at the time of the necropsy and fixed with $4 \%$ paraformaldehyde.

\section{Statistical analysis}

All results are presented as the mean \pm S.E.M. for at least three individual experiments. The difference between groups was analyzed using Student's $t$-test, and $P<0.05$ was considered statistically significant.

\section{Results}

\section{CD44 stem cell marker is highly expressed in TNBC} patients and correlates with poor survival outcomes

Previously, the clinical significance of CD44 expression in TNBC was evaluated using immunohistochemistry and shown to correlate with bad prognosis (Wang etal. 2017). To further address the clinical value of CD44 stem cell marker in TNBC, first we examined the gene expression level of CD44 in TNBC in comparison with non-TNBC patients in a large cohort of 4703 breast cancer patients using the Customize Expression Analysis tool of bc-GenExMiner4.1 database. Our analysis showed that CD44 gene expression level is significantly higher in TNBC patients (417 patients) compared with non-TNBC patients (4286 patients) $(P=0.0001)$ (Supplementary Fig. 1A, see section on supplementary data given at the end of this article). Next, we investigated the clinical relevance of CD44 gene expression in relation with patient outcomes, including any event-free survival (AEFS), metastasis-free survival (MFS) and relapse-free survival (RFS) using the Prognostic Analysis tool of bc-GenExMiner4.1 database in basal-like intrinsic breast cancer subgroup (representing TNBC). In addition, KM plotter database was also used for this analysis. Interestingly, we found a significant association between CD44 gene expression level and shortened AEFS (242 TNBC patients, $P=0.0462$ ) (Supplementary Fig. 1B), MFS (169 TNBC patients, $P=0.0211$ ) (Supplementary Fig. 1C) and RFS (618 TNBC patients $P=0.059)$ (Supplementary Fig. 1D). Next, to begin to evaluate the clinical relevance of PRL regulation of TNBC stemness, we investigated the association between PRLR and CD44 gene expression levels using the correlation module of bc-GenExMiner v4.1 database. Interestingly, as shown in Supplementary Fig. 1E, we observed a trend of negative correlation between PRLR and CD44 gene expression. Together, these findings indicate that expression of CD44 stem cell marker in TNBC patients displays an unfavorable
C) 2019 Society for Endocrinology Published by Bioscientifica Ltd. Printed in Great Britain 
outcome and suggests a potential regulatory role for PRL in TNBC stemness.

\section{PRL suppresses CD44+/CD24- as well as $\mathrm{ALDH}^{+} \mathrm{BCSC}$ subpopulations in TNBC cells}

$\mathrm{CD}_{4} 4^{+} / \mathrm{CD} 24^{-}$and $\mathrm{ALDH}^{+}$BCSC subpopulations are considered as the most tumorigenic cells within TNBC tumors. To examine the role of PRL in regulating these BCSC subpopulations in TNBC, we initially investigated the proportion of $\mathrm{CD}_{4} 4^{+} / \mathrm{CD} 24^{-}$as well as $\mathrm{ALDH}^{+} \mathrm{BCSCs}$ in TNBC cell lines representative of the mesenchymal stem-like/claudin-low TNBC subtype MDA-MB-231 and the previously generated MDA-MB-231/vector and MDA-MB-231/PRLR cells in comparison with TNBC cells representative of the luminal(LAR)-epithelial TNBC-PRLR subgroup expressing endogenously PRLR, MDA-MB-453 cells (Prat et al. 2010, Lehmann et al. 2011, Lopez-Ozuna et al. 2016). Interestingly, as can be seen in Fig. 1A, using flow cytometry analysis, we found that MDA-MB-231WT, MDA-MB-231/vector and MDA-MB-231/PRLR cells to be enriched in the mesenchymal and most tumorigenic CD44+CD24- BCSC population ( 80\%) in agreement with previous reports (Charafe-Jauffret et al. 2009). In contrast, MDA-MB-453 cells representing the luminalepithelial TNBC-PRLR subtype contained only $\sim 8 \%$ of these aggressive BCSCs but enriched with the least tumorigenic subpopulation CD44-/CD24- ( 90\%). No differences in the $\mathrm{ALDH}^{+}$epithelial-like BCSCs population were found between the cell types (around $2 \%$ in MDA-MB-231WT, MDA-MB-231/vector and MDA-MB-231/PRLR cells and $~ 3 \%$ in MDA-MB-453 cells). Together, these results suggest that cells representing the TNBC-PRLR subgroup have reduced levels of the aggressive mesenchymal BCSC subpopulation in comparison to the basal subtype and promoting us to examine the role of PRL in modulating the BCSC state in these TNBC cell model systems. Interestingly, upon PRL treatment of MDA-MB-231/PRLR cells, we observed a significant decrease in the tumorigenic BCSC subpopulation CD44+CD24- and the generation of the least tumorigenic subpopulation $\mathrm{CD} 44^{-/ \text {low/CD24- }}{ }^{-} \quad(\sim 60 \%, \quad P \leq 0.0001)$ compared with untreated cells (Fig. 1B, right and left panels). While no significant change was observed in the other subpopulations, a shift in a minor $\mathrm{CD} 44^{+} / \mathrm{CD} 24^{+}$ subpopulation to $\mathrm{CD} 44^{+} / \mathrm{CD} 24^{-}$in response to PRL treatment was observed. Next, as MDA-MB-453 cells did not show enrichment in the tumorigenic mesenchymal CD44+/CD24- population but did show the presence of $\mathrm{ALDH}^{+} \mathrm{BCSCs}(\sim 3 \%)$; therefore, we next examined whether PRL treatment of these cells is also able to modulate the $\mathrm{ALDH}^{+} \mathrm{BCSC}$ subpopulation. Interestingly, PRL was found to cause a significant reduction in $\mathrm{ALDH}^{+} \mathrm{BCSC}$ population by $80.3 \%(P=0.0003)$ (Fig. $1 \mathrm{C}$ ). Together, these results emphasized for the first time the important role of PRL in suppressing the mesenchymallike as well as the epithelial-like BCSCs and differentiating them into a phenotype associated with less tumorigenic potential.

\section{PRL suppresses stemness and viability of BCSC subpopulations in TNBC}

BCSCs possess self-renewal and tumor initiation capacity implicated in TNBC aggressive nature. Therefore, next we investigated whether PRL regulates these BCSCs properties in TNBC cells. Using RT-qPCR analysis, we examined the mRNA expression levels of Oct4, Sox 2 and Nanog - transcription factors important for self-renewal. Importantly, PRL treatment of MDA-MB-231/PRLR cells resulted in a significant downregulation of gene expression of all these transcription factors: Oct4 ( 5 folds), Sox2 (6.6 folds) and Nanog (6.9 folds) (Fig. 2A). In accordance with these data, we also observed a significant reduction in CD44 mRNA levels (2.3 folds) and a modest increase in CD24 levels (1.3 folds) in MDA-MB-231/PRLR following PRL treatment (Fig. 2A). Similarly, PRL stimulation of MDA-MB-453 cells also led to a significant reduction in gene expression of Oct4 (1.74 folds), Sox2 (1.8 folds), Nanog (2.39 folds) as well as CD44 (2.62 folds) mRNA levels (Fig. 2B). Together, these findings indicate that PRL can suppress the self-renewal transcriptional network in TNBC cells.

The ability to generate new tumors represents one of the cardinal features of CSCs. Therefore, we next examined the role of PRL in regulating the tumorsphere formation capacity of TNBC BCSCs. Using in vitro tumorsphere formation assay, MDA-MB-231/Vector and MDA-MB-231/ PRLR bulk cells were either untreated or treated with hPRL for $72 \mathrm{~h}$. These cells were then seeded under low attachment conditions in the presence or the absence of hPRL for analyses of primary and secondary tumorsphere formation. As shown in Fig. 2C, PRL treatment was able to reduce primary $(40.81 \%)(P=0.0006)$ and secondary $(74.2 \%) \quad(P=0.0001)$ tumorsphere formation ability of MDA-MB-231/PRLR cells. We next investigated the effects of PRL treatment in regulating in vitro tumorsphere formation capacity of the different CD44/CD24 subpopulations present in MDA-MB-231/PRLR. For this reason, we sorted the BCSC subpopulations including 
A

\begin{tabular}{|c|c|c|c|c|}
\cline { 2 - 5 } \multicolumn{1}{c|}{} & $\begin{array}{c}\text { MDA-MB- } \\
\mathbf{2 3 1 / W T}\end{array}$ & $\begin{array}{c}\text { MDA-MB- } \\
\mathbf{2 3 1 / v e c t o r}\end{array}$ & $\begin{array}{c}\text { MDA-MB- } \\
\mathbf{2 3 1} / \text { PRLR }\end{array}$ & $\begin{array}{c}\text { MDA-MB- } \\
\mathbf{4 5 3}\end{array}$ \\
\hline CD44+/CD24- & $75 \%$ & $67 \%$ & $77 \%$ & $8.5 \%$ \\
\hline CD44+/CD24+ & $27 \%$ & $36 \%$ & $24 \%$ & $1 \%$ \\
\hline CD44/CD24- & $1 \%$ & $1 \%$ & $1 \%$ & $89.2 \%$ \\
\hline CD44/CD24+ & 0 & 0 & 0 & $1.3 \%$ \\
\hline ALDH+ & $1.65 \%$ & $2.05 \%$ & $0.92 \%$ & $2.6 \%$ \\
\hline
\end{tabular}

B
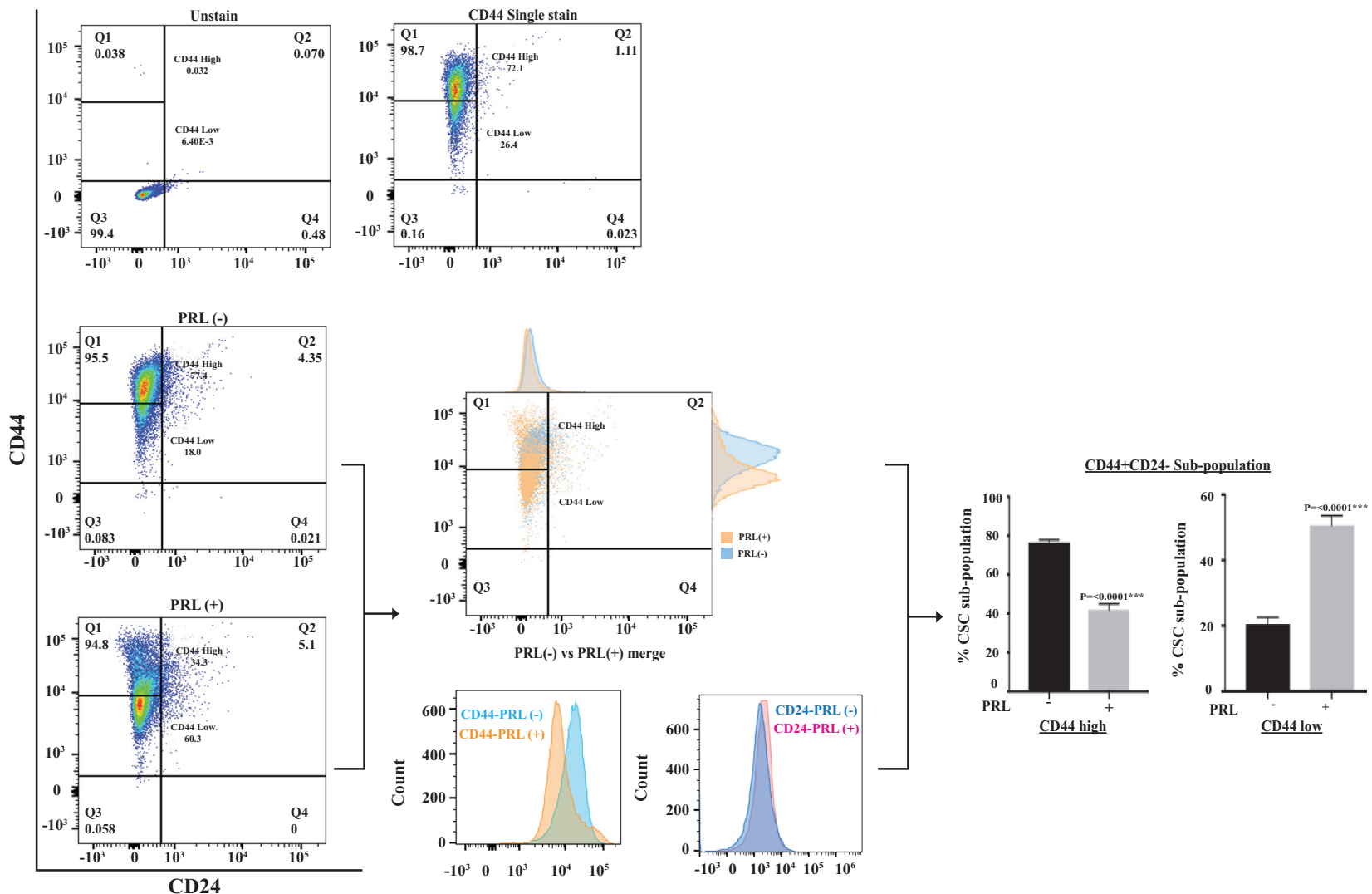

C
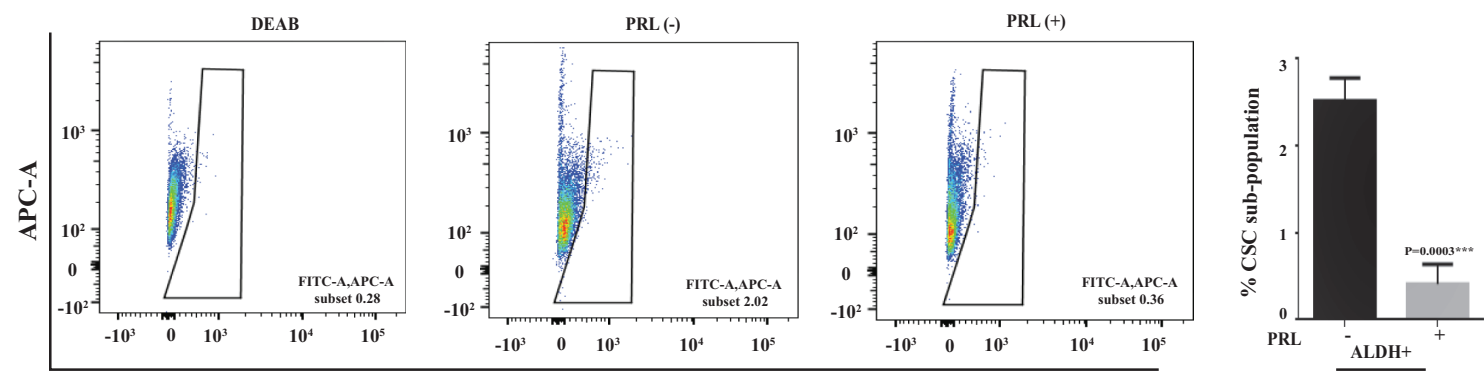

\section{Figure 1}

PRL suppresses the CD44+/CD24- and ALDH+ BCSCs in TNBC cells. (A) BCSC subpopulations (\%) present in MDA-MB-231 WT, MDA-MB-231/vector, MDA-MB-231/PRLR and MDA-MB-453 cells. A representative analysis of three independent experiments is shown. (B) MDA-MB-231/PRLR cells were treated or not with dox $(100 \mathrm{ng} / \mathrm{mL})$ and $\mathrm{hPRL}(250 \mathrm{ng} / \mathrm{mL})$ for $72 \mathrm{~h}$. Cells were then immunostained for CD44 and CD24 and processed for flow cytometry analysis (Material and methods). Left panel depicts representative dot plots. Middle panel incorporates fluorescent intensity of all subpopulations treated (orange) or not (blue) with hPRL. Representative histograms of CD44 and CD24 distribution levels are depicted. Right panels show quantification (\%) analysis of CD44+/CD24- BCSC subpopulation. Data represent the mean \pm S.E.M. of triplicates of three independent experiments. (C) MDA-MB-453 cells were treated or not with hPRL $(250 \mathrm{ng} / \mathrm{mL}$ ) for 5 days and ALDH positivity was assessed by ALDEFLOUR assay followed by flow cytometry analysis (Material and methods). Left panel shows a representative dot plot of ALDEFLOUR activity in the presence or absence of hPRL using DEAB-treated cells as a control. Right panel, quantification \% of $\mathrm{ALDH}^{+}$subpopulation, is depicted. Data represent the mean \pm S.E.M. of triplicates of three independent experiments.

https://erc.bioscientifica.com

https://doi.org/10.1530/ERC-18-0523
C) 2019 Society for Endocrinology Published by Bioscientifica Ltd Printed in Great Britain 

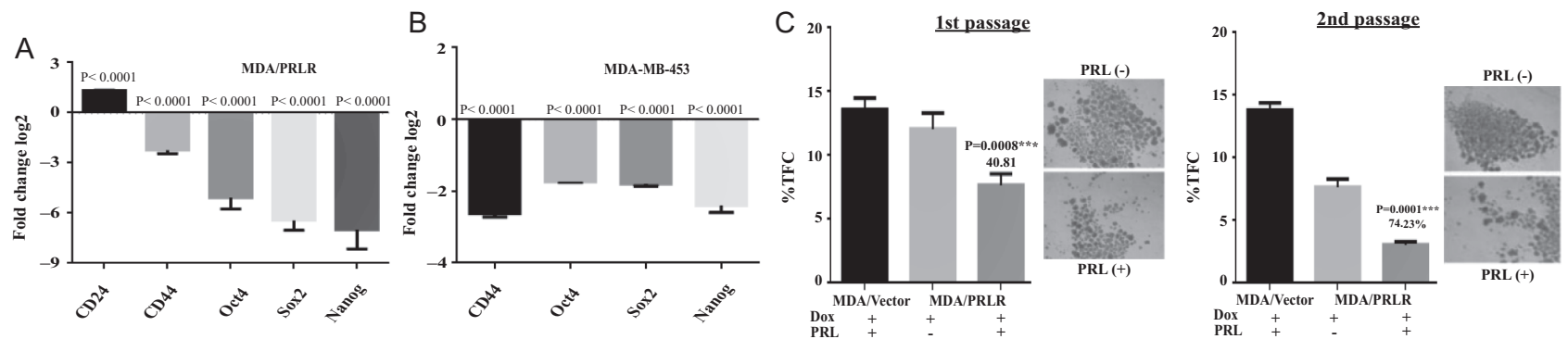

D

1 st passage

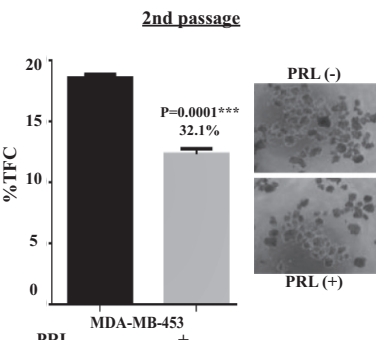

E

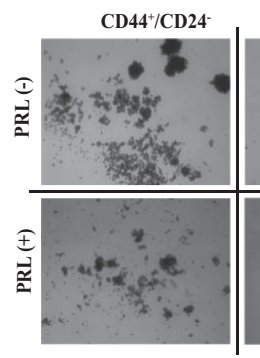

$\mathrm{CD}^{4} 4^{+} / \mathrm{CD} 24^{+}$

CD44/CD24

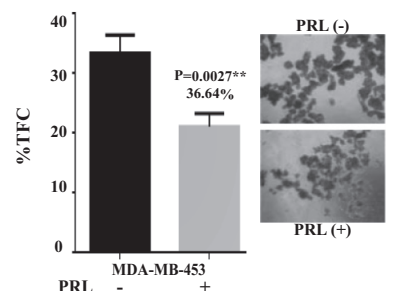

PRL
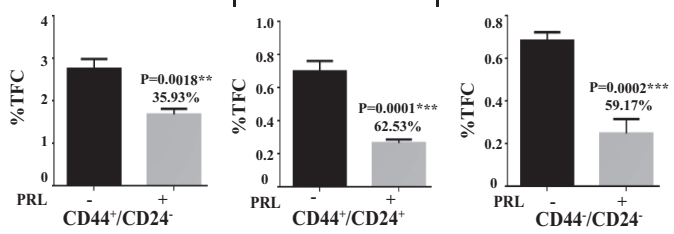

G

$\mathrm{H}$

$\underline{\text { ALDH }^{+-} \text {population sorted from MDA-MB-453 }}$
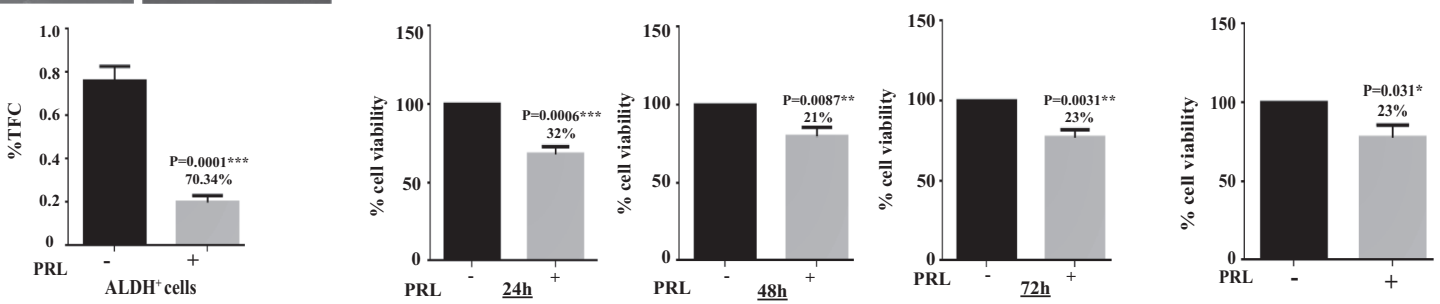

Figure 2

PRL inhibits stemness and viability of TNBC BCSCs. (A) MDA-MB-231/PRLR cells were treated or not with dox (100 ng/mL) and hPRL ( $250 \mathrm{ng} / \mathrm{mL})$ for $72 \mathrm{~h}$ and gene expression of stem cell markers and transcription factors (CD24, CD44, Oct4, Sox2 and Nanog) were examined using RT-qPCR $(P<0.05)$. Results are expressed as log2 fold change of triplicates of three independent experiments. (B) MDA-MB-453 cells were treated or not with hPRL ( $250 \mathrm{ng} / \mathrm{mL}$ ) for 5 days and the expression of stem cell markers and transcription factors (CD24, CD44, Oct4, Sox2 and Nanog) was examined using RT-qPCR $(P<0.05)$. Results are expressed as log2 fold change of triplicates of three independent experiments. (C) MDA-MB-231/vector and MDA-MB-231/PRLR were treated or not with dox $(100 \mathrm{ng} / \mathrm{mL})$ and $\mathrm{hPRL}(250 \mathrm{ng} / \mathrm{mL})$ for $72 \mathrm{~h}$ before tumorsphere formation assay was performed for 7 days. Left and right panels depict primary and secondary tumorsphere formation capacity (Material and methods). Data represent the mean \pm S.E.M. of triplicates of three independent experiments. Representative microphotographs of primary and secondary tumorspheres are shown. (D) MDA-MB-453 cells were treated or not with hPRL ( $250 \mathrm{ng} / \mathrm{mL}$ ) for 5 days before tumorsphere formation assay was performed for 7 days. Left and right panels depict primary and secondary tumorsphere formation, respectively. Data represent the mean \pm S.E.M. of triplicates of three independent experiments. Representative microphotographs of primary and secondary tumorspheres respectively are shown. (E) CD44+/CD24-, CD44+/CD24+ and CD44-/CD24- cell subpopulations were sorted from MDA-MB-231/PRLR and subjected to tumorsphere formation assay under hPRL stimulation. Upper panel, representative microphotographs of primary tumorspheres are shown. Lower panel, quantification data (\%) represents the mean \pm S.E.M. of triplicates of three independent experiments. (F) ALDH ${ }^{+}$ subpopulation isolated from MDA-MB-453 was subjected to tumorsphere formation assay under hPRL stimulation. Upper panel, representative microphotographs of primary tumorspheres are shown. Lower panel, quantification data (\%) represents the mean \pm s.E.M. of triplicates of three independent experiments. (G) The CD44+/CD24- cell subpopulation sorted from MDA-MB-231/PRLR were plated and treated or not with hPRL $(250 \mathrm{ng} / \mathrm{mL})$ for 24,48 and $72 \mathrm{~h}$. MTT assays were performed and the results are presented as means \pm S.E.M. for triplicates of three independent experiments. (H) $\mathrm{ALDH}^{+}$cell subpopulation was isolated from MDA-MB-453 and treated or not with hPRL ( $250 \mathrm{ng} / \mathrm{mL}$ ) for 5 days. MTT assays were performed and the results are presented as means \pm S.E.M. for triplicates of three independent experiments. 
$\mathrm{CD}_{4} 4^{+} / \mathrm{CD} 24^{-}, \mathrm{CD}_{4} 4^{+} / \mathrm{CD} 24^{+}$and CD44-/CD24- ${ }^{-}$and examined their tumorsphere formation capacity in the presence or absence of hPRL. Importantly, PRL treatment was able to decrease significantly the tumor formation capacity of all CD44/CD24 subpopulations ( 40\%, $P=0.0001,62 \%, P=0.0045$ and $59 \% P=0.0166$ respectively) (Fig. 2E). Next, we examined the ability of PRL to regulate tumorsphere formation capacity of MDA-MB-453 cells representative of the TNBC-PRLR subgroup. As shown in Fig. 2D, PRL was also able to significantly suppress primary $(36.6 \%) \quad(P=0.0001)$ and secondary $(32.1 \%)$ $(P=0.0001)$ tumorsphere formation in comparison with non-treated cells. In the same manner, PRL treatment was also sufficient to cause a significant reduction (70\%) $((P=0.0001)$ in the tumorsphere formation capacity of $\mathrm{ALDH}^{+}$cells sorted from MDA-MB-453 bulk cells (Fig. 2F). These results together highlight the critical inhibitory effect of PRL on self-renewal and tumorsphere formation capacity of $\mathrm{CD}_{4} 4^{+} / \mathrm{CD} 24^{-}$and $\mathrm{ALDH}^{+}$TNBC BCSC subpopulations.

Next, we evaluated the role of PRL in regulating cell viability of the most tumorigenic CSC subpopulations. The CD44+/CD24- and ALDH+ BCSC subpopulations were sorted from MDA-MB-231/PRLR and MDA-MB-453 cells, respectively, using flow cytometry and then subjected to a cell viability assay. Interestingly, our results showed that PRL treatment induced a significant decrease in cell

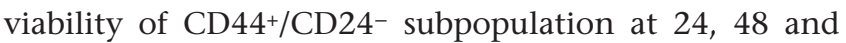
$72 \mathrm{~h}(32 \%, P=0.0006,21 \%, P=0.0087$ and $23 \% P=0.0031$ respectively) in comparison with untreated cells (Fig. $2 \mathrm{G}$ ). The same significant reduction in viability of $\mathrm{ALDH}^{+}$ BCSCs was also observed following PRL treatment (23\%) $(P=0.031)$ (Fig. 2H). Altogether, these results demonstrate that PRL limits self-renewal, tumorsphere formation capacity as well as viability of TNBC BCSC subpopulations.

\section{PRL induces cell cycle arrest and modulates the expression of regulators of cell cycle progression in TNBC cells}

To further decipher the possible mechanisms mediating the anti-tumorigenic role of PRL in TNBC, we next evaluated the effect of $\mathrm{PRL}$ in regulating apoptosis and cell cycle in TNBC cells MDA-MB-231/PRLR and MDA-MB-453. Initially, the effects of PRL treatment on apoptosis were assessed using caspase 3/7 assays. Our results showed no significant change in caspase 3/7 activity in MDA-MB-231/PRLR cells treated with hPRL for 24,48 and $72 \mathrm{~h}$ in comparison with untreated cells (Supplementary Fig. 2A). Similarly, PRL did not change caspase3/7 activation in MDA-MB-453 cells (Supplementary Fig. 2C). To further substantiate the above findings, we quantified the apoptotic cells using Annexin V/PI double staining assay. Indeed, neither MDA-MB-231/PRLR cells nor MDA-MB-453 cells showed any significant increase in Annexin $\mathrm{V}$ staining in comparison to control cells following 72-h treatment with hPRL (Supplementary Fig. 1B and D, respectively). Together, these data indicate that PRL is not a major inducer of apoptosis in TNBC cells.

Next, we analyzed the effects of PRL treatment on cell cycle progression, which might represent a mechanism through which PRL mediates its anti-tumorigenic effects. For this, MDA-MB-231/PRLR and MDA-MB-453 cells were synchronized and treated with hPRL for $72 \mathrm{~h}$ and subjected to cell cycle analysis using flow cytometry. Our results reveled that PRL treatment led to a significant increase in G1 arrest $(\sim 5 \%)$ in both cellular models in comparison with their control untreated cells (Fig. 3A and B) $(P=0.0001)$. For better understanding of the role of PRL in regulating cell cycle, we next evaluated the effect of PRL on cell cycle regulatory genes using RT-qPCR analysis. Interestingly, our results revealed a significant upregulation of mRNA levels of retinoblastoma (Rb) (1.52 folds), cyclindependent kinase inhibitor 1 (p21) (1.69 folds), cyclindependent kinase 4 inhibitor B (p15INK4b) (2.49 folds) and cyclin-dependent kinase inhibitor INK4 (2.38 folds), whereas a significant downregulation of cyclin E mRNA (-1.5 folds) was observed in MDA-MB-231/PRLR following PRL treatment. No significant change in mRNA level of cyclin-dependent kinase inhibitor 2A gene (p16INK4a) was detected (Fig. 3C). Furthermore, PRL treatment of MDA-MB-453 cells also showed the same significant trend of upregulation of $\mathrm{Rb}$ (1.53 folds) and downregulation of cyclin E ( -1.5 folds) mRNA levels in comparison with untreated cells (Fig. 3D). Next, to evaluate the clinical relevance of PRL regulation of cell cycle regulators in TNBC clinical cases, we investigated the association between $\mathrm{Rb}$ gene expression and that of PRL and its signaling pathway PRLR, Jak2 kinase and Stat5 in 374 samples of TNBC patients using the correlation analysis tool of bc-GenExMiner v4.1 database. Interestingly, our results showed a trend of positive correlation in gene expression between PRL and its signaling cascade (PRLR, Jak2 and Stat5) and Rb. This association was statistically significant in the case of gene expression of PRL and Jak2 ( $P=0.0369, P=0.0015$ respectively) (Fig. 3E). In the same manner, we next examined the association between https://erc bioscientifica com

https://doi.org/10.1530/ERC-18-0523 (c) 2019 Society for Endocrinology Published by Bioscientifica Ltd. Printed in Great Britain 
A

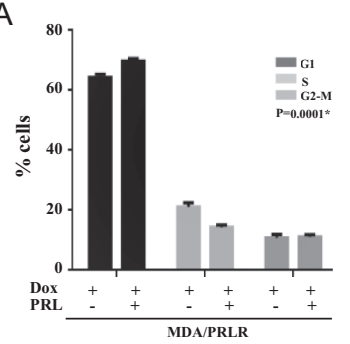

E

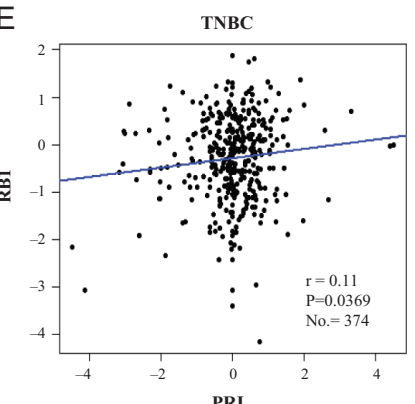

B

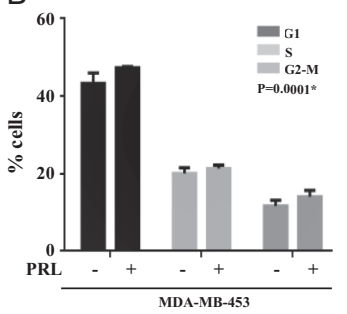

C

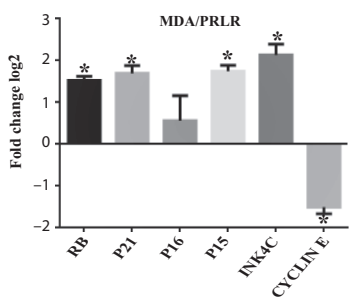

D

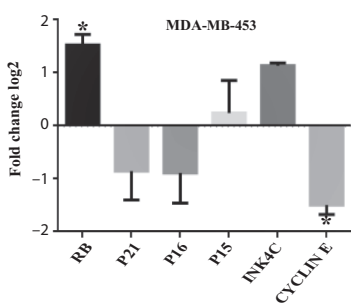

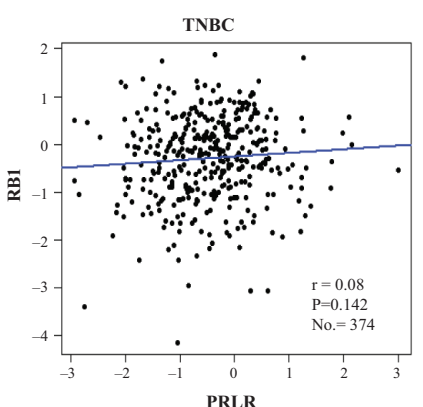
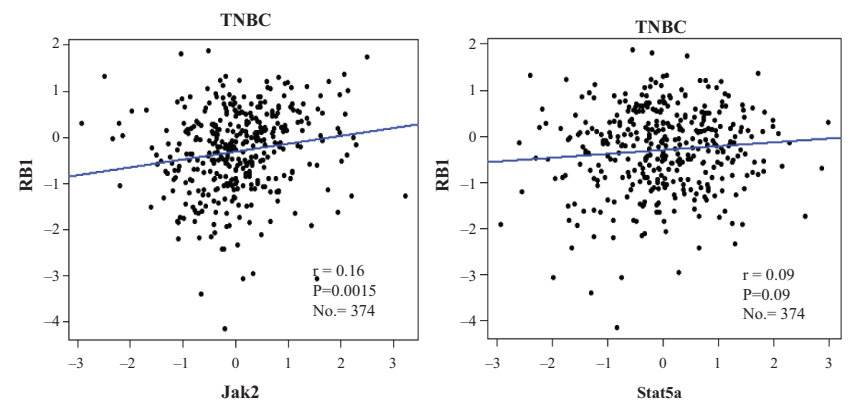

F
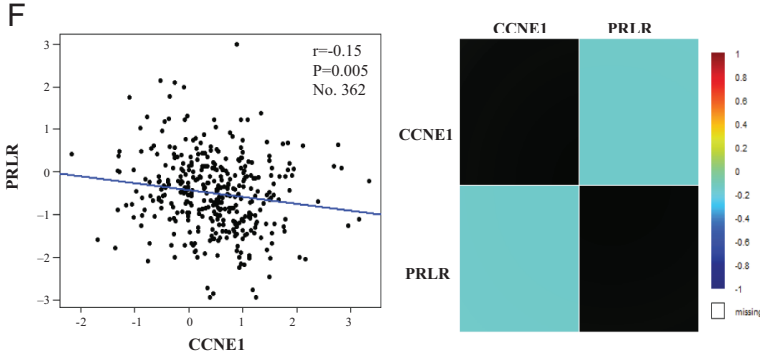

\section{Figure 3}

Prolactin induces cell cycle arrest and correlates positively with cell cycle regulators in TNBC patients. (A) MDA-MB-231/PRLR cells were synchronized and treated with dox $(100 \mathrm{ng} / \mathrm{mL})$ overnight and then treated or not with $\mathrm{hPRL}(250 \mathrm{ng} / \mathrm{mL})$ for $72 \mathrm{~h}$ followed by cell cycle analysis. Data represent the mean \pm S.E.M. of triplicates of one representative experiment. (B) MDA-MB-453 cells were synchronized and treated or not with hPRL (250 ng/mL) for 5 days followed by cell cycle analysis. Data represent the mean \pm S.E.M. of triplicates of one representative experiment. (C) MDA-MB-231/PRLR cells were treated or not with dox $(100 \mathrm{ng} / \mathrm{mL})$ and hPRL $(250 \mathrm{ng} / \mathrm{mL})$ for $72 \mathrm{~h}$ and the expression of cell cycle-associated genes (RB, p21, p16, p15, INK4C and cyclin E) were examined using qRT-PCR $(P<0.05)$. Results are presented as means \pm S.E.M. for triplicates of three independent experiments. (D) MDA-MB-453 cells were treated or not with hPRL $(250 \mathrm{ng} / \mathrm{ml})$ for 5 days and the expression of cell cycle-associated genes (RB, p21, p16, p15 and INK4C) were examined using RT-qPCR $(P<0.05)$. Results are presented as means \pm s.E.M. for triplicates of three independent experiments. (G) The correlation between RB1 gene expression levels and PRL, PRLR, Jak2 and Stat5a in 374 TNBC samples using the correlation analysis tool of bc-GenExMiner4.1 database. (F) Correlation between PRLR gene expression levels and cyclin E in TNBC patient samples using Pearson's pairwise correlation plot and heat map in bc-GenExMiner4.1 database.

PRLR mRNA expression levels and cyclin E mRNA levels, a marker of breast cancer recurrence and poor survival outcome (Keyomarsi et al. 2002) in clinical samples of 362 TNBC patients using the correlation analysis tool of bc-GenExMiner4.1 database. Interestingly, PRLR expression showed a significant negative association with cyclin E mRNA levels $(P=0.0054)$ (Fig. 3F). Altogether, these results highlight the inhibitory effects of PRL on cell cycle progression in TNBC.

\section{PRL induces heterochromatin formation,} differentiation/senescence-associated morphological changes and resistance to growth signals in TNBC cells

Chromatin dynamics and epigenetic programs play critical roles during development, differentiation, cell fate as well as plasticity of cancer stem cells (Barrero et al. 2010). Heterochromatin formation is marked by specific histone modifications, including histone H3 lysine 9 
trimethylation (H3K9me3). This histone methylation is known to cause gene silencing and transition from pluripotency to affect differentiation and cell identity. Due to the differentiation role of PRL in mammary and breast cancer cells, we next examined the role of PRL in regulating heterochromatin formation in TNBC cells. First, we measured histone H3 methylation using antibody-detecting H3K9me3 by confocal microscopy. MDA-MB-231/PRLR cells and MDA-MB-453 cells were treated with PRL for $72 \mathrm{~h}$ and 5 days, respectively. Interestingly, we found that PRL treatment led to a significant increase in $\mathrm{H} 3 \mathrm{~K} 9 \mathrm{me} 3$ deposition in MDA-MB-231/PRLR cells as well as in MDA-MB-453 cells and quantified by the levels of H3K9me3-DAPI colocalization in comparison with untreated cells (five folds and three folds increase respectively, $P=0.0001$ ) (Fig. 4A). This PRL-induced increase in H3k9 trimethylation in MDA-MB-231/PRLR and MDA-MB-453 cells was also confirmed using western blot analysis (Fig. 4B). Moreover, and for further evaluation of the effect of PRL treatment on regulation of heterochromatin formation, we next analyzed whether PRL modulates the mRNA expression levels of the histone methyltransferase SUV39H1, known to methylate Lys-9 of histone H3, as well as the heterochromatin protein 1 (HP1), known to interact with $\mathrm{H} 3 \mathrm{~K} 9 \mathrm{me} 3$ and to induce gene repression (Becker et al. 2016). Our findings revealed a significant upregulation of SUV39H1 (1.52 folds) and HP1 (1.5 folds) mRNA levels in MDA-MB-231/PRLR cells after PRL stimulation (Fig. 4C). Equally, we also found PRL to induce the upregulation of mRNA levels of SUV39H1 (2.13 folds) as well as HP1 (1.5 folds) in MDA-MB-453 cells (Fig. 4C). Together these findings suggest there is a role for PRL in the induction of heterochromatin formation in TNBC cells through H3K9me3 epigenetic regulation.

Deposition of heterochromatin coupled with cellular differentiation has been shown to induce characteristic ultra-structural cellular morphology (Olins et al. 1998, Stephens et al. 2018). Since PRL is a well-known differentiation factor for mammary epithelial cells and its ability to induce heterochromatin in TNBC cells, we next examined whether PRL induces ultra-structural changes associated with cellular differentiation. MDA-MB-453 cells were treated or not with hPRL for 5 days and processed for electron microscopy (EM) analysis. As can be seen in Fig. 5D right panel, control untreated MDA-MB-453 cells displayed a nucleus with well-formed nucleolus (nl) surrounded by homogenous chromatin and is enveloped by a regular membrane $(\mathrm{nm})$. The cytoplasm contained highly dense mitochondria $(\mathrm{mt})$ with classical divisions of internal cristae (crests), regular lysosomes (ly)-containing granules and complete rough reticulum (rr) seen in the periphery. The Golgi apparatus (go) also is displayed as sacks in the periphery with a normal shape. Interestingly, as shown in Fig. 4D left panel, PRL-treated cells displayed identifiable ultra-structural changes including irregularly shaped nuclei being multi-lobed or 'blebbed' with high chromatin density indicative of heterochromatin formation in the periphery and reduced size or loss of the nucleolus. Moreover, in PRL-treated cells, the mitochondria appeared to have lost their transverse cristae and showed translucent areas. Since abnormal nuclear protrusions (blebs) can be associated with both lamin and chromatin alterations, we next attempted to evaluate the role of PRL in regulating the expression of lamin B1 involved in the integrity of the nuclear membrane and chromatin arrangement. Using RT-qPCR, we analyzed the mRNA level of lamin B1 following treatment of MDA-MB-231/PRLR and MDA-MB-453 cells with PRL for $72 \mathrm{~h}$ and 5 days, respectively. Our results showed a significant downregulation of lamin B1 in both TNBC cellular model systems $(-2.29$ folds and -1.92 folds respectively $P=0.0001$ ) (Fig. 4E). Together, these results highlight that PRL induces ultra-structural changes indicative of heterochromatin formation and differentiation.

Next, we investigated the effects of PRL on other effector mechanisms of heterochromatin formation and differentiation including cellular senescence and resistance to growth signals. To achieve this aim we studied the effect of PRL on the induction of senescenceassociated $\beta$-galactosidase (SA- $\beta$-gal) activity in TNBC cells. As shown in Fig. 4F, we found a significant increase in SA- $\beta$-gal activity in MDA-MB-231/PRLR following PRL treatment in comparison with untreated cells $(\sim 32 \%)$ $(P=0.0001)$. The same pattern of SA- $\beta$-gal increment was observed in MDA-MB-453 cells following PRL treatment in comparison with untreated cells $(\sim 36 \%)$ (Fig. $4 \mathrm{G}$ ) $(P=0.0001)$. No significant increase in SA- $\beta$-gal activity was found when cells were treated for 24 and $48 \mathrm{~h}$ with hPRL in both cellular models (Supplementary Fig. 2E and F). To examine the role of PRL in inducing an irreversible non-proliferative state in TNBC cells, MDA-MB-231/PRLR cells and MDA-MB-453 cells pre-treated with hPRL for $72 \mathrm{~h}$ or 5 days, respectively. Cells were then plated for a week in growth factor-enriched media. Interestingly, as shown in Fig. $4 \mathrm{H}$ and I, we found that PRL pre-treated cells show resistance to growth signals as measured by loss of cell viability, $25.3 \%(P=0.0001)$ (MDA-MB-231/PRLR cells) and $24.8 \% \quad(P=0.0001) \quad(\mathrm{MDA}-\mathrm{MB}-453$ cells) (c) 2019 Society for Endocrinology Published by Bioscientifica Ltd. Printed in Great Britain 
A
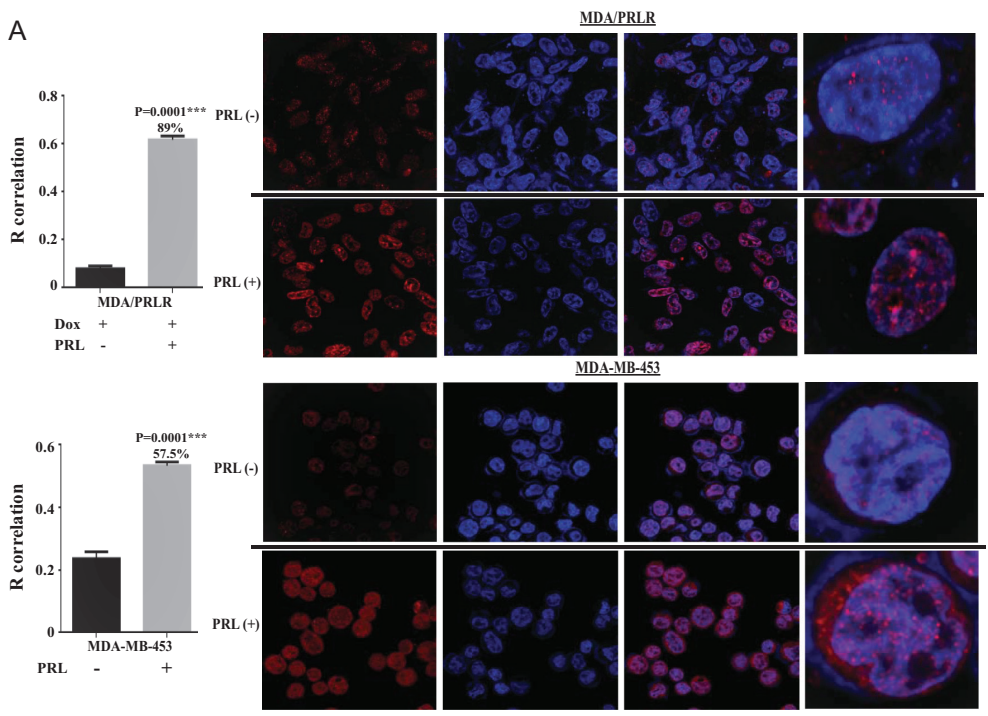

D
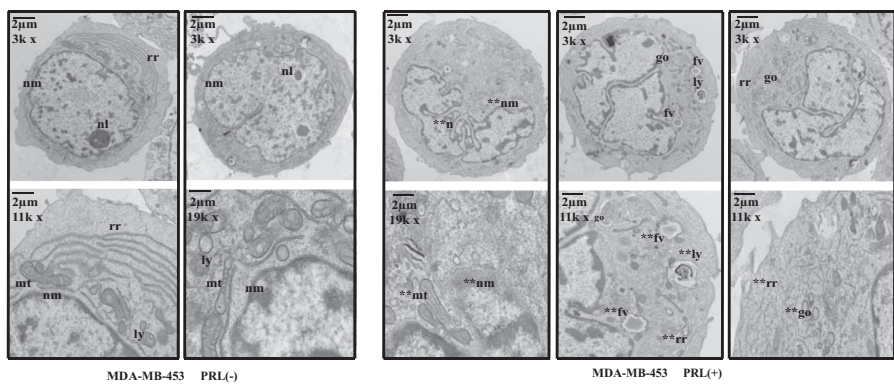

B

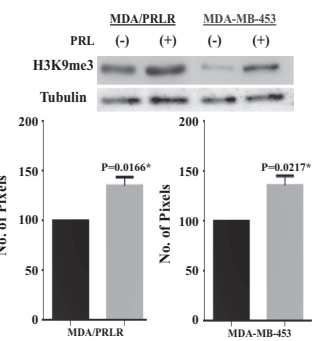

$\substack{\text { Dox } \\ \text { PRL }}$
Pand

C

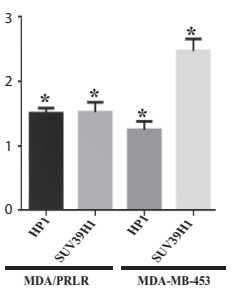

E
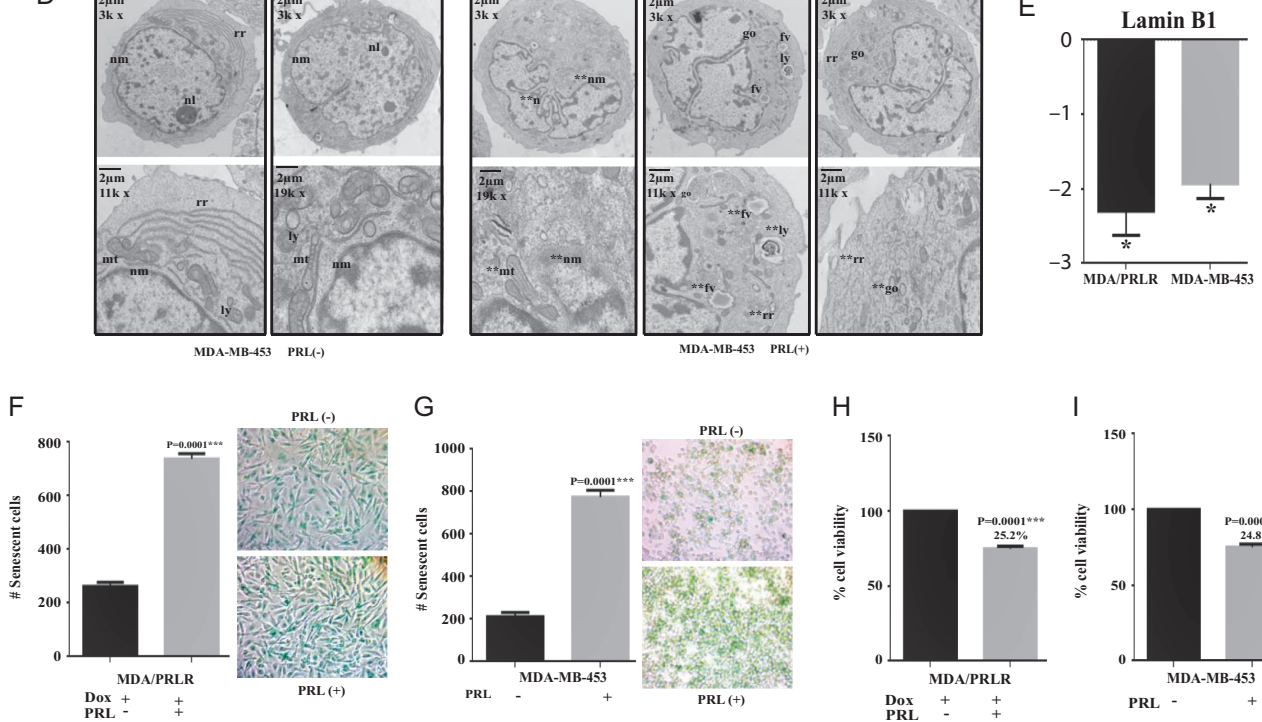

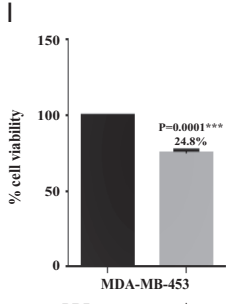

PRL

\section{Figure 4}

PRL induces H3K9me3 heterochromatin formation and senescence-associated ultra-structural phenotype in TNBC cells. (A) H3K9me3 staining was assessed using confocal microscopy in MDA-MB-231/PRLR and MDA-MB-453 cells following hPRL stimulation. Right panels depict H3K9me3-DAPI colocalization. Data are presented as mean \pm S.E.M. of three independent experiments. (B) MDA-MB-231/PRLR and MDA-MB-453 cells were stimulated or not with hPRL $(250 \mathrm{ng} / \mathrm{mL}$ ) for $72 \mathrm{~h}$ and 5 days, respectively. Cell lysates were immune detected using antibodies to H3K9me3 and $\beta$-tubulin. Data are presented as mean \pm s.E.M. of three independent experiments. (C) MDA-MB-231/PRLR and MDA-MB-453 cells were treated or not with hPRL (250 ng/mL) for $72 \mathrm{~h}$ and 5 days, respectively. Gene expression of SUV39H1 and HP1 were examined using RT-qPCR. Results are presented as means \pm S.E.M. for triplicates of three independent experiments $(P<0.05)$. (D) MDA-MB-453 cells were treated or not with $\mathrm{hPRL}(250 \mathrm{ng} / \mathrm{mL})$ for 5 days and processed for EM. Left panel depicted EM images of MDA-MB-453 untreated cells (2 different cells); nuclear membrane (nm), nucleolus (nl), mitochondria (mt), lysosome (ly) and rough endoplasmic reticulum ( $\mathrm{rr}$ ) can be appreciated. Right panel represents EM images of MDA-MB-453 cells treated with PRL for 5 days ( 3 different cells); multi-lobulated nucleus (**n), loss on continuity in the nuclear membrane (**nm), irregular mitochondria, Golgi apparatus and rough endoplasmic reticulum patterns $\left({ }^{* *} \mathrm{mt}, * *\right.$ go, $\left.{ }^{* *} \mathrm{rr}\right)$, presence of fatty vesicles ( ${ }^{* * \mathrm{fv}}$ ). (E) MDA-MB-231/PRLR and MDA-MB-453 cells were treated or not with hPRL ( $250 \mathrm{ng} / \mathrm{mL}$ ) for $72 \mathrm{~h}$ and 5 days, respectively. Lamin B1 gene expression was examined using RT-qPCR. Data are presented as mean \pm S.E.M. of three independent experiments $(P<0.05)$. (F) MDA-MB-231/PRLR cells were treated or not with dox $(100 \mathrm{ng} / \mathrm{mL})$ and hPRL $(250 \mathrm{ng} / \mathrm{mL})$ for $72 \mathrm{~h}$ followed by assessment of positive SA $\beta$-gal staining. Data are presented as mean \pm S.E.M. of triplicates of three independent experiments. Representative images are shown. (G) MDA-MB-453 cells were treated or not with hPRL $(250 \mathrm{ng} / \mathrm{mL})$ for 5 days followed by assessment of positive SA $\beta$-gal staining. Data are presented as mean \pm S.E.M. of triplicates of three independent experiments. Representative images are shown. (H) MDA-MB-231/PRLR cells were plated and treated or not treated with dox $(100 \mathrm{ng} / \mathrm{mL})$ and $\mathrm{hPRL}(250 \mathrm{ng} / \mathrm{mL})$ for $72 \mathrm{~h}$. Next, cells were re-plated in full growth media (DMEM-10\% FBS) for 1 week. MTT assays were performed and the results are presented as means \pm S.E.M. of triplicates of three independent experiments $(P=0.0001)$. (I) MDA-MB-453 cells were plated and treated or not treated with hPRL $(250 \mathrm{ng} / \mathrm{mL})$ for 5 days. Next, cells were re-plated in full growth media (DMEM-10\% FBS) for 1 week. MTT assays were performed and the results are presented as means \pm s.E.M. of triplicates of three independent experiments $(P=0.0001)$. 
compared with untreated cells. Altogether, these results emphasize an important regulatory role for PRL in the induction of H3K9me3 heterochromatin deposition and cellular morphological and biological characteristics of cellular differentiation and senescence.

\section{PRL suppresses tumorigenesis in vivo resulting in the loss of proliferation and stemness while triggering stable heterochromatin formation in TNBC pre-clinical xenografts}

The above data highlighted an important role for PRL in suppressing stemness and inducing epigenetic program associated with regulating stem cell reprograming, differentiation and cell fate in vitro. Therefore, next we aimed to elucidate whether PRL is able to regulate these mechanisms and inhibit tumor growth in vivo. First, we analyzed the effects of PRL in regulating tumorigenesis in vivo using MDA-MB-231 cells in a pre-clinical TNBC animal xenograft model. NOD/SCID mice were inoculated with either MDA-MB-231/vector or MDA-MB-231/PRLR cells into the right mammary fat pad. After 8 weeks of cell implantation, 10/10 mice of the MDA-MB-231/vector group developed tumors compared to MDA-MB-231/PRLR group that only 15/20 mice developed tumors. Animals were randomly assigned into three groups: MDA-MB-231/ vector treated with dox and hPRL (10 mice), MDA-MB-231/ PRLR treated with only dox (7 mice) and MDA-MB-231/ PRLR treated with dox and hPRL (8 mice) and treatments commenced once palpable tumors were developed (Fig. 5). Tumor growth was monitored for 3 weeks during the treatment period (Material and methods). Importantly, as shown in Fig. 5A and B, a significant retardation in tumor growth was observed in MDA-MB-231/PRLRtreated group (mean tumor volume of $697 \pm 101 \mathrm{~mm}^{3}$ ) in comparison with untreated group (mean tumor volume of $1158.56 \pm 95.9 \mathrm{~mm}^{3}$ ) and MDA-MB-231/vector group (mean tumor volume of $1829.9 \pm 195 \mathrm{~mm}^{3}$ ) at the time of killing $(P=0.0001)$. These results suggest that PRL abrogates tumor growth in vivo.

Next, we evaluated whether PRL-mediated suppression of tumorigenesis observed in vivo correlated with loss of cell proliferation, stemness and induction of heterochromatin modification. Initially, we evaluated the PRLR protein expression in MDA-MB-231/vector and MDA-MB-231/PRLR xenografts. As expected, while more than $90 \%$ of the malignant cells in MDA-MB-231/PRLR tumors showed positive PRLR expression, tumors obtained from MDA-MB-231/vector showed very low detectable levels of PRLR expression ( 10\%) (Fig. 5C).
Interestingly, IHC analysis of Ki67, a widely used marker of cell proliferation, revealed a significant loss of expression in tumor xenografts of MDA-MB-231/PRLR when compared to MDA-MB-231/vector $(P=0.0026)$. Importantly, this reduction in Ki67 expression was doubled in tumor sections from PRL-treated tumor xenografts compared to vector xenografts $(P=0.0002)$ (Fig. 5D). Next, we evaluated whether restoration and activation of PRL pathway in TNBC tumor xenografts can cause a reduction in TNBC stemness by examining the levels of CD44 protein expression. Indeed, as shown in Fig. 5E, PRLR restoration was sufficient to significantly reduce CD44 levels by around 30\% $(P=0.0004)$ in comparison to vector xenografts. Moreover, tumor sections from the MDA-MB-231/PRLR xenografts treated with PRL showed additional reduction of nearly $60 \%$ of CD44 levels compared to the vector group $(P<0.0001)$ (Fig. 5E). Finally, we evaluated the methylation pattern of $\mathrm{H} 3$ using H3K9me3 antibody, in samples of tumors obtained from our animal xenograft models. Interestingly, as can be seen in Fig. 5F, xenograft tumors from MDA-MB-231/PRLR-treated group showed significantly higher levels of methylation compared to MDA-MB-231/PRLR untreated and MDA-MB-231/vector xenografts $(P=0.0002)$, emphasizing the ability of PRL to induce heterochromatin formation in vivo in TNBC tumors. Altogether, these results provide pre-clinical evidence regarding the ability of PRL hormone in suppressing proliferation, stemness and inducing stable heterochromatin modification of TNBC tumors resulting in the suppression of tumorigenesis in vivo. These results emphasize the possible clinical benefits of the PRL as a differentiation therapy that might help in converting the highly aggressive TNBC cells enriched with cancer stem cells into more differentiated and non-tumorigenic cells.

\section{Discussion}

TNBC is associated with aggressive behavior attributed to different histological and molecular features including loss of cell differentiation and the presence of high levels of cancer stem-like cell populations within the tumor bulk (Charafe-Jauffret et al. 2009, Brouckaert et al. 2012). Indeed, regulation of cancer stem cell transition between aggressive un-differentiated states to a differentiated phenotype with less aggressive features might help in providing new approaches to treat TNBC (Agur et al. 2011). This study highlights an important role for PRL hormone in reprograming BCSCs subpopulations (c) 2019 Society for Endocrinology Published by Bioscientifica Ltd. Printed in Great Britain 
A

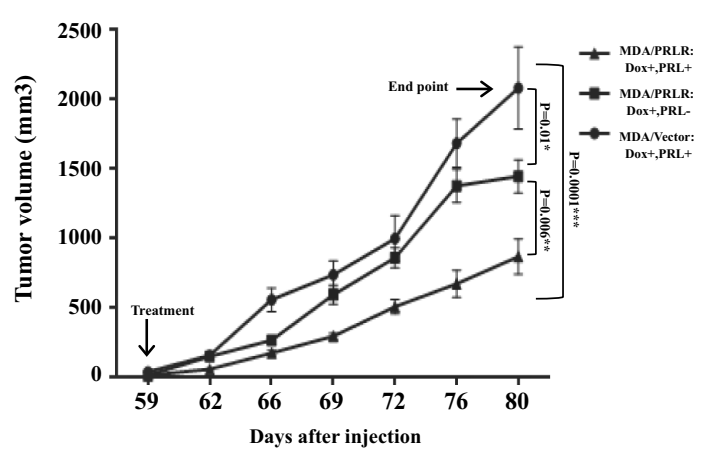

B

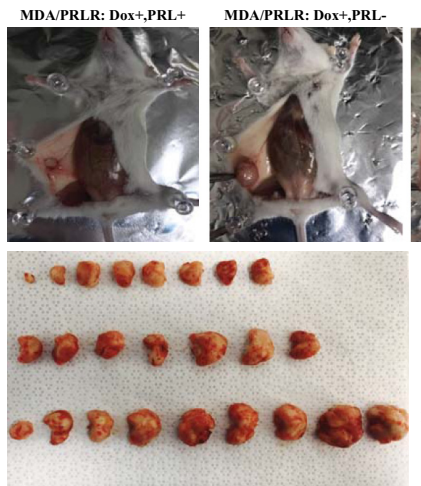

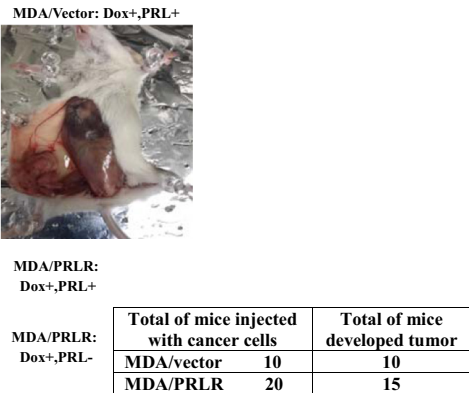

MDA/Vector: Dox + PRL +
C
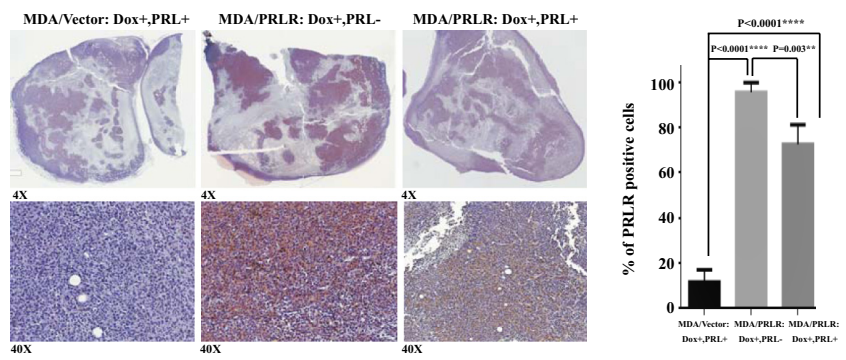

D
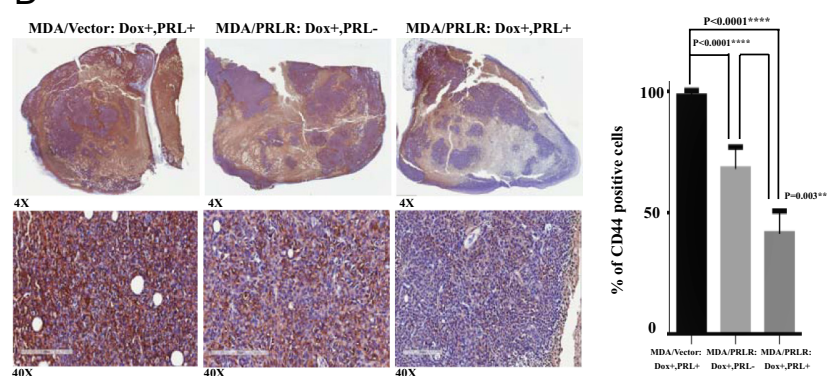

E
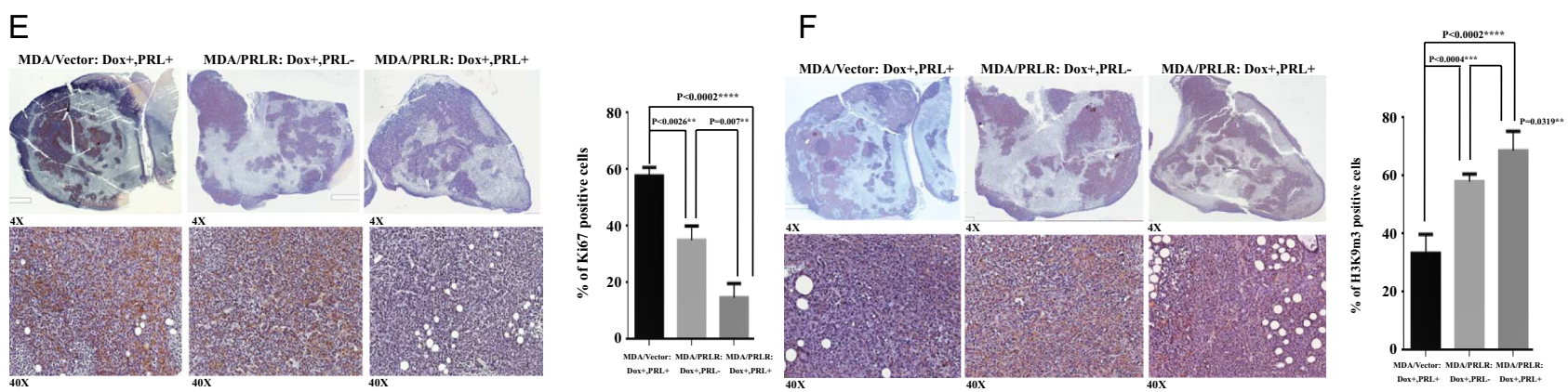

\section{Figure 5}

PRL suppresses tumor growth and markers of proliferation and stemness while induces genomic heterochromatin hypermethylation in vivo. (A) Graph depicting tumor volume of xenografts of MDA-MB-231/Vector and MDA-MB-231/PRLR treated or untreated with hPRL. (B) Representative pictures of NOD/SCID mice bearing tumors (upper panel). Pictures are shown of dissected tumors from the different experimental groups (lower panel). Table: Indicates the number of mice injected with cancer cells and the number of mice that showed tumor development. (C) Immunohistochemical staining and quantification of PRLR expression in tumors xenografts is shown (4x and 40×). (D) Immunohistochemical staining and quantification of CD44 expression in tumors xenografts is shown (4× and 40×). (E) Immunohistochemical staining and quantification of Ki67 expression in tumors xenografts is shown (4× and 40×). (F) Immunohistochemical staining and quantification of H3K9m3 expression in tumors xenografts is shown (4× and 40×).

present in TNBC and suppressing their replicative and tumorsphere formation capacity through the induction of differentiation-linked epigenetic programs. These effects of PRL seen in vitro were corroborated in a preclinical in vivo animal xenograft model, in which PRL was found to exert growth inhibitory and stable epigenetic modifications in TNBC tumors resulting in the suppression of tumorigenesis.

The identification and contribution of BCSCs to tumor heterogeneity and aggressiveness is still to be fully defined. Nonetheless several markers have been proposed to label these tumor cells including EpCAM/ESA, CD133 (prominin-1), CD61/ק3 integrin in addition to CD44, CD24 and ALDH positivity mostly studied markers in TNBC (Da Cruz Paula \& Lopes 2017). PRL is considered a major regulator of terminal differentiation and cell fate determination factor for the mammary epithelial cells. The role of PRL in regulating BCSCs is yet to be established (Sackmann-Sala et al. 2015). We have previously found that PRL promotes mammary luminal progenitor $\left(\mathrm{EpCAM}^{\mathrm{h}} / \mathrm{CD} 49 \mathrm{f}^{\mathrm{h}}\right)$ cells commitment into mature luminal (EpCAM ${ }^{\mathrm{h}} / \mathrm{CD} 49 \mathrm{f}^{\mathrm{l}}$ ) cells (Liu et al. 2015a). As mammary 
stem cells are reflective of their cancer counterpart, the presence of EpCAM-/low/CD49fh in breast tumors was found to be associated with poor clinical prognosis (Ye et al. 2015). Additionally, our results obtained here also revealed that PRL was able to suppress the tumorigenic $\mathrm{CD}_{4} 4^{+} / \mathrm{CD} 24^{-}$and $\mathrm{ALDH}^{+}$BCSC subpopulations and to induce their reprograming into non-tumorigenic phenotype CD44-/low/CD24-. Interestingly, PRLR gene expression was also found to have inverse relationship with CD44 gene expression in TNBC clinical samples. Together, these results implicate PRL in depleting the tumorigenic BCSC subpopulations into less aggressive phenotype with less tumorigenic capacity in TNBC. These effects of PRL are also supported by the findings that luminal differentiation transcription factors identified initially to regulate normal mammary differentiation such as ELF5 and GATA3 also induce BCSCs differentiation, reducing their tumorigenic potential (Asselin-Labat et al. 2011, Chakrabarti et al. 2012a,b). Together, these studies highlight that regulators/inducers of mammary luminal differentiation may provide targets for the development of therapeutics to control and suppress stemness and aggressive features of TNBC.

Heterochromatin represents regions of the chromosomes that are especially compacted and transcriptionally repressed. These regions are marked by specific histone modifications including methylation of H3 (H3K9me3). Interestingly, this methylation pattern has been shown to impact two highly related cell fate mechanisms: cellular differentiation and senescence. Indeed, H3K9me3-decorated heterochromatin was found to be important in controlling cell fate determination and terminal differentiation through epigenetic gene silencing (Allan et al. 2012, Liu et al. 2015b, Becker et al. 2016). In this study, we found PRL treatment of TNBC cells to result in the induction of $\mathrm{H} 3 \mathrm{~K} 9 \mathrm{me} 3$ and increased gene expression of SUV39H1 methylase and HP1 implicating epigenetic regulation of heterochromatin as a mechanism by which PRL may exert its differentiative and antitumorigenic role in TNBC. Furthermore, we propose that PRL may also regulate cell cycle progression through epigenetic mechanism. Indeed, $\mathrm{Rb} / \mathrm{H} 3 \mathrm{~K} 9 \mathrm{me} 3 / \mathrm{HP} 1$ axis was previously implicated in the suppression of cyclin $\mathrm{E}$ promoter activation (Stewart et al. 2005, Panteleeva et al. 2007). Indeed, we propose that PRL through the induction of $\mathrm{Rb}$ and SUV39H1 expression leads to the induction of H3K9-trimethylation and recruitment of HP1 to the DNA, in turn leading to the suppression of cyclin E gene expression resulting in cell growth arrest.
Moreover, our data also suggest that the induction of differentiation and senescence by PRL might be parallel or overlapping processes. The ability of PRL to induce senescence as measured by SA- $\beta$-gal observed here was reported previously as unexpected and nonconclusive finding (Nitze et al. 2013). Indeed, our study showed that PRL treatment was able to induce SA- $\beta$-gal and found to cause key ultra-structural morphological adaptations associated with heterochromatin formation, differentiation and senescence ((Olins et al. 1998, Sadaie et al. 2013, Stephens et al. 2018). Interestingly, under PRL influence TNBC cells exhibited lobulated nuclei, linked to differentiation (Olins et al. 1998), small or absence of nucleolus, associated with reduced ribosomal synthesis (Stepinski 2018) and translucent mitochondria, associated with loss of oxidative phosphorylation and altered metabolic activity (Rossignol et al. 2004). Together, these results lead us to hypothesize a sequence of events initiated by PRL in TNBC cells. These events include the induction of TNBC cell differentiation into a less aggressive phenotype. Furthermore, these cells will become susceptible to undergo cellular senescence leading to permanent growth arrest and resistance to oncogenic signals.

While this study is based on the use of full-length PRL ( $23 \mathrm{kDa}$ ) hormone, PRL is also known to be proteolytically cleaved to produce a fragment of $16 \mathrm{kDa}$ with known anti-angiogenic effects (Bernard et al. 2015). It will be important to further characterize the function of the $16 \mathrm{kDa}$ fragment in relation to function of the full-length PRL in breast cancer. Furthermore, we have focused in this study on the role mediated by the long form of the PRLR. This form of the receptor has been most studied and is known to activate Jak2/Stat5 pathway and to mediate PRL's well-known mammary differentiation effects. The roles of the other PRLR isoforms (Meng et al. 2004, Ginsburg et al. 2010) have been less studied though their potential inhibitory effects regarding the long form has long been known (Berlanga et al. 1997, Tan \& Walker 2010, Kang et al. 2014). Altogether, our results highlight the ability of PRL to promote reprograming of TNBC cells from highly proliferative and stem celllike phenotype into more differentiated, less aggressive and non-proliferative phenotype. The ability of PRL to induce these changes emphasizes the potential use of PRL hormone as a novel differentiation therapy for TNBC patients able to inhibit tumor progression and recurrence. Future studies may support the use of PRL as an adjuvant therapy to treat certain subtypes of TNBC, together with (c) 2019 Society for Endocrinology Published by Bioscientifica Ltd. Printed in Great Britain 
chemotherapy and other new targeted drugs such as cell cycle checkpoints inhibitors.

\section{Supplementary data}

This is linked to the online version of the paper at https://doi.org/10.1530/ ERC-18-0523.

\section{Declaration of interest}

The authors declare that there is no conflict of interest that could be perceived as prejudicing the impartiality of the research reported.

\section{Funding}

Dr Vanessa M López-Ozuna is supported by a CONACYT scholarship from the Mexican Government. Dr Ibrahim Hachim is supported by the Fonds de Recherche du Québec - Santé (FRQS) scholarship. J J Lebrun is the recipient of the McGill Sir William Dawson Research Chair. This work was supported by 'The Canadian Institutes of Health Research' (CIHR, grants \# 233437 and \#233438) granted to Suhad Ali.

\section{Author contribution statement}

V M L-O supported in research design, performed experiments and wrote the manuscript. I Y H performed analyses of $\mathrm{IHC}$ and contributed to drafting the manuscript, M Y H performed bioinformatics data analyses, J-J $\mathrm{L}$ contributed to design and revised the manuscript, $\mathrm{S}$ A helped in research design, supervision and revising the manuscript.

\section{References}

Agur Z, Kirnasovsky OU, Vasserman G, Tencer-Hershkowicz L, Kogan Y, Harrison H, Lamb R \& Clarke RB 2011 Dickkopf1 regulates fate decision and drives breast cancer stem cells to differentiation: an experimentally supported mathematical model. PLoS One 6 e24225. (https://doi.org/10.1371/journal.pone.0024225)

Al-Hajj M, Wicha MS, Benito-Hernandez A, Morrison SJ \& Clarke MF 2003 Prospective identification of tumorigenic breast cancer cells. PNAS 100 3983-3988. (https://doi.org/10.1073/pnas.0530291100)

Allan RS, Zueva E, Cammas F, Schreiber HA, Masson V, Belz GT, Roche D, Maison C, Quivy JP, Almouzni G, et al. 2012 An epigenetic silencing pathway controlling T helper 2 cell lineage commitment. Nature 487 249-253. (https://doi.org/10.1038/nature11173)

Anders CK \& Carey LA 2009 Biology, metastatic patterns, and treatment of patients with triple-negative breast cancer. Clinical Breast Cancer 9 (Supplement 2) S73-S81. (https://doi.org/10.3816/CBC.2009.s.008)

Asselin-Labat ML, Sutherland KD, Vaillant F, Gyorki DE, Wu D, Holroyd S, Breslin K, Ward T, Shi W, Bath ML, et al. 2011 Gata-3 negatively regulates the tumor-initiating capacity of mammary luminal progenitor cells and targets the putative tumor suppressor caspase-14. Molecular and Cellular Biology 31 4609-4622. (https://doi. org/10.1128/MCB.05766-11)

Barrero MJ, Boue S \& Izpisua Belmonte JC 2010 Epigenetic mechanisms that regulate cell identity. Cell Stem Cell 7 565-570. (https://doi. org/10.1016/j.stem.2010.10.009)

Becker JS, Nicetto D \& Zaret KS 2016 H3K9me3-dependent heterochromatin: barrier to cell fate changes. Trends in Genetics 32 29-41. (https://doi.org/10.1016/j.tig.2015.11.001)
Ben-Porath I, Thomson MW, Carey VJ, Ge R, Bell GW, Regev A \& Weinberg RA 2008 An embryonic stem cell-like gene expression signature in poorly differentiated aggressive human tumors. Nature Genetics 40 499-507. (https://doi.org/10.1038/ng.127)

Berlanga JJ, Garcia-Ruiz JP, Perrot-Applanat M, Kelly PA \& Edery M 1997 The short form of the prolactin (PRL) receptor silences PRL in of the beta-casein gene promoter. Molecular Endocrinology 11 1449-1457. (https://doi.org/10.1210/mend.11.10.9994)

Bernard V, Young J, Chanson P \& Binart N 2015 New insights in prolactin: pathological implications. Nature Reviews Endocrinology 11 265-275. (https://doi.org/10.1038/nrendo.2015.36)

Brouckaert O, Wildiers H, Floris G \& Neven P 2012 Update on triplenegative breast cancer: prognosis and management strategies. International Journal of Women's Health 4 511-520. (https://doi. org/10.2147/IJWH.S18541)

Burstein MD, Tsimelzon A, Poage GM, Covington KR, Contreras A, Fuqua SA, Savage MI, Osborne CK, Hilsenbeck SG, Chang JC, Mills GB, Lau CC \& Brown PH 2015 Comprehensive genomic analysis identifies novel subtypes and targets of triple-negative breast cancer. Clinical Cancer Research 21 1688-1698

Chakrabarti R, Hwang J, Andres Blanco M, Wei Y, Lukacisin M, Romano RA, Smalley K, Liu S, Yang Q, Ibrahim T, et al. 2012a Elf5 inhibits the epithelial-mesenchymal transition in mammary gland development and breast cancer metastasis by transcriptionally repressing Snail2. Nature Cell Biology 14 1212-1222. (https://doi. org/10.1038/ncb2607)

Chakrabarti R, Wei Y, Romano RA, DeCoste C, Kang Y \& Sinha S 2012b Elf5 regulates mammary gland stem/progenitor cell fate by influencing notch signaling. Stem Cells 30 1496-1508. (https://doi. $\operatorname{org} / 10.1002 /$ stem.1112)

Charafe-Jauffret E, Ginestier C, Iovino F, Wicinski J, Cervera N, Finetti P, Hur MH, Diebel ME, Monville F, Dutcher J, et al. 2009 Breast cancer cell lines contain functional cancer stem cells with metastatic capacity and a distinct molecular signature. Cancer Research 69 1302-1313. (https://doi.org/10.1158/0008-5472.CAN-08-2741)

Cocolakis E, Lemay S, Ali S \& Lebrun JJ 2001 The p38 MAPK pathway is required for cell growth inhibition of human breast cancer cells in response to activin. Journal of Biological Chemistry 276 18430-18436. (https://doi.org/10.1074/jbc.M010768200)

Da Cruz Paula A \& Lopes C 2017 Implications of different cancer stem cell phenotypes in breast cancer. Anticancer Research 37 2173-2183. (https://doi.org/10.21873/anticanres.11552)

Galsgaard ED, Rasmussen BB, Folkesson CG, Rasmussen LM, Berchtold MW, Christensen L \& Panina S 2009 Re-evaluation of the prolactin receptor expression in human breast cancer. Journal of Endocrinology 201 115-128. (https://doi.org/10.1677/JOE-080479)

Ginestier C, Hur MH, Charafe-Jauffret E, Monville F, Dutcher J, Brown M, Jacquemier J, Viens P, Kleer CG, Liu S, et al. 2007 ALDH1 is a marker of normal and malignant human mammary stem cells and a predictor of poor clinical outcome. Cell Stem Cell 1 555-567. (https://doi.org/10.1016/j.stem.2007.08.014)

Ginsburg E, Alexander S, Lieber S, Tarplin S, Jenkins L, Pang L, Heger CD, Goldsmith P \& Vonderhaar BK 2010 Characterization of ductal and lobular breast carcinomas using novel prolactin receptor isoform specific antibodies. BMC Cancer 10 678. (https://doi. org/10.1186/1471-2407-10-678)

Goffin V 2017 Prolactin receptor targeting in breast and prostate cancers: new insights into an old challenge. Pharmacology and Therapeutics 179 111-126. (https://doi.org/10.1016/j. pharmthera.2017.05.009)

Hachim IY, Hachim MY, Lopez VM, Lebrun JJ \& Ali S 2016a Prolactin Receptor Expression is an Independent Favorable Prognostic Marker in Human Breast Cancer. Applied Immunohistochemistry and Molecular Morphology 24 238-245. (https://doi.org/10.1097/ PAI.0000000000000178) (c) 2019 Society for Endocrinology Published by Bioscientifica Ltd. Printed in Great Britain 
Hachim IY, Shams A, Lebrun JJ \& Ali S 2016b A favorable role of prolactin in human breast cancer reveals novel pathway-based gene signatures indicative of tumor differentiation and favorable patient outcome. Human Pathology 53 142-152. (https://doi.org/10.1016/j. humpath.2016.02.010)

Hankinson SE, Willett WC, Michaud DS, Manson JE, Colditz GA, Longcope C, Rosner B \& Speizer FE 1999 Plasma prolactin levels and subsequent risk of breast cancer in postmenopausal women. Journal of the National Cancer Institute 91 629-634. (https://doi.org/10.1093/ jnci/91.7.629)

Hennighausen L \& Robinson GW 2005 Information networks in the mammary gland. Nature Reviews Molecular Cell Biology 6 715-725. (https://doi.org/10.1038/nrm1714)

Honeth G, Bendahl PO, Ringner M, Saal LH, Gruvberger-Saal SK, Lovgren K, Grabau D, Ferno M, Borg A \& Hegardt C 2008 The CD44+/CD24- phenotype is enriched in basal-like breast tumors. Breast Cancer Research 10 R53. (https://doi.org/10.1186/bcr2108)

Jezequel P, Campone M, Gouraud W, Guerin-Charbonnel C, Leux C, Ricolleau G \& Campion L 2012 bc-GenExMiner: an easy-to-use online platform for gene prognostic analyses in breast cancer. Breast Cancer Research and Treatment 131 765-775. (https://doi.org/10.1007/ s10549-011-1457-7)

Kang JH, Hassan SA, Zhao P, Tsai-Morris CH \& Dufau ML 2014 Impact of subdomain D1 of the short form S1b of the human prolactin receptor on its inhibitory action on the function of the long form of the receptor induced by prolactin. Biochimica et Biophysica Acta 1840 2272-2280. (https://doi.org/10.1016/j.bbagen.2014.04.006)

Keyomarsi K, Tucker SL, Buchholz TA, Callister M, Ding Y, Hortobagyi GN, Bedrosian I, Knickerbocker C, Toyofuku W, Lowe M, et al. 2002 Cyclin E and survival in patients with breast cancer. New England Journal of Medicine 347 1566-1575. (https://doi.org/10.1056/ NEJMoa021153)

Kim RJ \& Nam JS 2011 OCT4 expression enhances features of cancer stem cells in a mouse model of breast cancer. Laboratory Animal Research 27 147-152. (https://doi.org/10.5625/lar.2011.27.2.147)

Kim Y, Joo KM, Jin J \& Nam DH 2009 Cancer stem cells and their mechanism of chemo-radiation resistance. International Journal of Stem Cells 2 109-114. (https://doi.org/10.15283/ijsc.2009.2.2.109)

Lehmann BD, Bauer JA, Chen X, Sanders ME, Chakravarthy AB, Shyr Y \& Pietenpol JA 2011 Identification of human triple-negative breast cancer subtypes and preclinical models for selection of targeted therapies. Journal of Clinical Investigation 121 2750-2767. (https:// doi.org/10.1172/JCI45014)

Liu F, Pawliwec A, Feng Z, Yasruel Z, Lebrun JJ \& Ali S 2015a Prolactin/ Jak2 directs apical/basal polarization and luminal linage maturation of mammary epithelial cells through regulation of the Erk1/2 pathway. Stem Cell Research 15 376-383. (https://doi.org/10.1016/j. scr.2015.08.001)

Liu J, Magri L, Zhang F, Marsh NO, Albrecht S, Huynh JL, Kaur J, Kuhlmann T, Zhang W, Slesinger PA, et al. 2015b Chromatin landscape defined by repressive histone methylation during oligodendrocyte differentiation. Journal of Neuroscience 35 352-365. (https://doi.org/10.1523/JNEUROSCI.2606-14.2015)

Lopez-Ozuna VM, Hachim IY, Hachim MY, Lebrun JJ \& Ali S 2016 Prolactin pro-differentiation pathway in triple negative breast cancer: impact on prognosis and potential therapy. Scientific Reports 6 30934. (https://doi.org/10.1038/srep30934)

Lu X, Mazur SJ, Lin T, Appella E \& Xu Y 2014 The pluripotency factor nanog promotes breast cancer tumorigenesis and metastasis. Oncogene 33 2655-2664. (https://doi.org/10.1038/onc.2013.209)

Ma F, Li H, Li Y, Ding X, Wang H, Fan Y, Lin C, Qian H \& Xu B 2017 Aldehyde dehydrogenase 1 (ALDH1) expression is an independent prognostic factor in triple negative breast cancer (TNBC). Medicine 96 e6561. (https://doi.org/10.1097/MD.0000000000006561)

Meng J, Tsai-Morris CH \& Dufau ML 2004 Human prolactin receptor variants in breast cancer: low ratio of short forms to the long-form human prolactin receptor associated with mammary carcinoma. Cancer Research 64 5677-5682. (https://doi.org/10.1158/0008-5472. CAN-04-1019)

Nitze LM, Galsgaard ED, Din N, Lund VL, Rasmussen BB, Berchtold MW, Christensen L \& Panina S 2013 Reevaluation of the proposed autocrine proliferative function of prolactin in breast cancer. Breast Cancer Research and Treatment 142 31-44. (https://doi.org/10.1007/ s10549-013-2731-7)

Nouhi Z, Chughtai N, Hartley S, Cocolakis E, Lebrun JJ \& Ali S 2006 Defining the role of prolactin as an invasion suppressor hormone in breast cancer cells. Cancer Research 66 1824-1832. (https://doi. org/10.1158/0008-5472.CAN-05-2292)

Oakes SR, Robertson FG, Kench JG, Gardiner-Garden M, Wand MP, Green JE \& Ormandy CJ 2007 Loss of mammary epithelial prolactin receptor delays tumor formation by reducing cell proliferation in low-grade preinvasive lesions. Oncogene 26 543-553. (https://doi. org/10.1038/sj.onc.1209838)

Olins AL, Buendia B, Herrmann H, Lichter P \& Olins DE 1998 Retinoic acid induction of nuclear envelope-limited chromatin sheets in HL-60. Experimental Cell Research 245 91-104. (https://doi. org/10.1006/excr.1998.4210)

Ormandy CJ, Binart N \& Kelly PA 1997 Mammary gland development in prolactin receptor knockout mice. Journal of Mammary Gland Biology and Neoplasia 2 355-364. (https://doi. org/10.1023/A:1026395229025)

Panteleeva I, Boutillier S, See V, Spiller DG, Rouaux C, Almouzni G, Bailly D, Maison C, Lai HC, Loeffler JP, et al. 2007 HP1alpha guides neuronal fate by timing E2F-targeted genes silencing during terminal differentiation. EMBO Journal 26 3616-3628. (https://doi. org/10.1038/sj.emboj.7601789)

Peck AR, Witkiewicz AK, Liu C, Klimowicz AC, Stringer GA, Pequignot E, Freydin B, Yang N, Ertel A, Tran TH, et al. 2012 Low levels of Stat5a protein in breast cancer are associated with tumor progression and unfavorable clinical outcomes. Journal of Mammary Gland Biology and Neoplasia 14 R130. (https://doi.org/10.1186/bcr3328)

Prat A, Parker JS, Karginova O, Fan C, Livasy C, Herschkowitz JI, He X \& Perou CM 2010 Phenotypic and molecular characterization of the claudin-low intrinsic subtype of breast cancer. Breast Cancer Research 12 R68. (https://doi.org/10.1186/bcr2635)

Rakha EA, El-Sayed ME, Green AR, Lee AH, Robertson JF \& Ellis IO 2007 Prognostic markers in triple-negative breast cancer. Cancer 109 25-32. (https://doi.org/10.1002/cncr.22381)

Rangel MC, Bertolette D, Castro NP, Klauzinska M, Cuttitta F \& Salomon DS 2016 Developmental signaling pathways regulating mammary stem cells and contributing to the etiology of triplenegative breast cancer. Breast Cancer Research and Treatment 156 211-226. (https://doi.org/10.1007/s10549-016-3746-7)

Rodriguez-Pinilla SM, Sarrio D, Moreno-Bueno G, Rodriguez-Gil Y, Martinez MA, Hernandez L, Hardisson D, Reis-Filho JS \& Palacios J 2007 Sox2: a possible driver of the basal-like phenotype in sporadic breast cancer. Modern Pathology 20 474-481. (https://doi.org/10.1038/ modpathol.3800760)

Rose-Hellekant TA, Arendt LM, Schroeder MD, Gilchrist K, Sandgren EP \& Schuler LA 2003 Prolactin induces ERalpha-positive and ERalphanegative mammary cancer in transgenic mice. Oncogene 22 4664-4674. (https://doi.org/10.1038/sj.onc.1206619)

Rossignol R, Gilkerson R, Aggeler R, Yamagata K, Remington SJ \& Capaldi RA 2004 Energy substrate modulates mitochondrial structure and oxidative capacity in cancer cells. Cancer Research 64 985-993. (https://doi.org/10.1158/0008-5472.CAN-03-1101)

Sackmann-Sala L, Guidotti JE \& Goffin V 2015 Minireview: prolactin regulation of adult stem cells. Molecular Endocrinology 29 667-681. (https://doi.org/10.1210/me.2015-1022)

Sadaie M, Salama R, Carroll T, Tomimatsu K, Chandra T, Young AR, Narita M, Perez-Mancera PA, Bennett DC, Chong H, et al. 2013 Redistribution of the Lamin $\mathrm{B} 1$ genomic binding profile affects https://erc bioscientifica com

https://doi.org/10.1530/ERC-18-0523
C) 2019 Society for Endocrinology Published by Bioscientifica Ltd. Printed in Great Britain 
rearrangement of heterochromatic domains and SAHF formation during senescence. Genes and Development 27 1800-1808. (https:// doi.org/10.1101/gad.217281.113)

Stephens AD, Liu PZ, Banigan EJ, Almassalha LM, Backman V, Adam SA, Goldman RD \& Marko JF 2018 Chromatin histone modifications and rigidity affect nuclear morphology independent of lamins. Molecular Biology of the Cell 29 220-233. (https://doi.org/10.1091/ mbc.E17-06-0410)

Stepinski D 2018 The nucleolus, an ally, and an enemy of cancer cells. Histochemistry and Cell Biology 150 607-629. (https://doi. org/10.1007/s00418-018-1706-5)

Stewart MD, Li J \& Wong J 2005 Relationship between histone H3 lysine 9 methylation, transcription repression, and heterochromatin protein 1 recruitment. Molecular and Cellular Biology 25 2525-2538. (https://doi.org/10.1128/MCB.25.7.2525-2538.2005)

Sutherland A, Forsyth A, Cong Y, Grant L, Juan TH, Lee JK, Klimowicz A, Petrillo SK, Hu J, Chan A, et al. 2016 The role of prolactin in bone metastasis and breast cancer cell-mediated osteoclast differentiation. Journal of the National Cancer Institute $\mathbf{1 0 8}$ djv338. (https://doi.org/10.1093/jnci/djv338)

Tan D \& Walker AM 2010 Short form 1b human prolactin receptor down-regulates expression of the long form. Journal of Molecular Endocrinology 44 187-194. (https://doi.org/10.1677/JME-09-0101)

Tworoger SS, Eliassen AH, Zhang X, Qian J, Sluss PM, Rosner BA \& Hankinson SE 2013 A 20-year prospective study of plasma prolactin as a risk marker of breast cancer development. Cancer Research $\mathbf{7 3}$ 4810-4819. (https://doi.org/10.1158/0008-5472.CAN-13-0665)
Vomachka AJ, Pratt SL, Lockefeer JA \& Horseman ND 2000 Prolactin gene-disruption arrests mammary gland development and retards T-antigen-induced tumor growth. Oncogene 19 1077-1084. (https:// doi.org/10.1038/sj.onc.1203348)

Wang H, Wang L, Song Y, Wang S, Huang X, Xuan Q, Kang X \& Zhang Q 2017 CD44(+)/CD24(-) phenotype predicts a poor prognosis in triple-negative breast cancer. Oncology Letters 14 5890-5898. (https://doi.org/10.3892/ol.2017.6959)

Wennbo H, Gebre-Medhin M, Gritli-Linde A, Ohlsson C, Isaksson OG \& Tornell J 1997 Activation of the prolactin receptor but not the growth hormone receptor is important for induction of mammary tumors in transgenic mice. Journal of Clinical Investigation $\mathbf{1 0 0}$ 2744-2751. (https://doi.org/10.1172/JCI119820)

Yamashita H, Nishio M, Ando Y, Zhang Z, Hamaguchi M, Mita K, Kobayashi S, Fujii Y \& Iwase H 2006 Stat5 expression predicts response to endocrine therapy and improves survival in estrogen receptor-positive breast cancer. Endocrine-Related Cancer 13 885-893. (https://doi.org/10.1677/erc.1.01095)

Ye F, Qiu Y, Li L, Yang L, Cheng F, Zhang H, Wei B, Zhang Z, Sun L \& $\mathrm{Bu} \mathrm{H} 2015$ The presence of $\operatorname{EpCAM(-)/CD49f(+)~cells~in~breast~cancer~}$ is associated with a poor clinical outcome. Journal of Breast Cancer $\mathbf{1 8}$ 242-248. (https://doi.org/10.4048/jbc.2015.18.3.242)

Yonezawa T, Chen KH, Ghosh MK, Rivera L, Dill R, Ma L, Villa PA, Kawaminami M \& Walker AM 2015 Anti-metastatic outcome of isoform-specific prolactin receptor targeting in breast cancer. Cancer Letters 366 84-92. (https://doi.org/10.1016/j. canlet.2015.06.010)

Received in final form 11 December 2018

Accepted 14 January 2019

Accepted Preprint published online 14 January 2019 (c) 2019 Society for Endocrinology Published by Bioscientifica Ltd. Printed in Great Britain 